\title{
ENHANCING DISTRIBUTION NETWORK PERFORMANCE: A QUANTITATIVE APPROACH TO DEVELOPING A DISTRIBUTION STRATEGY MODEL
}

\author{
DOI: 10.17261/Pressacademia.2020.1331 \\ JMML- V.7-ISS.4-2020(1)-p.160-182
}

\section{Yang Xiong ${ }^{1}$, Chukwuneke Okorie ${ }^{2}$, Golda Ezeoke ${ }^{3}$}

${ }^{1}$ Milanoo.com Complex, Chengdu City, Sichuan, China. xiongyangokm1@hotmail.com, ORCID: 0000-0002-2007-4854

${ }^{2}$ Plymouth Business School, Plymouth University, Plymouth, United Kingdom. chukwuneke.okorie@plymouth.ac.uk,ORCID: 0000-0002-8078-1323

${ }_{3}^{3}$ University of Lagos, Department of Business Administration, Operations and Production Management, Lagos, Nigeria. egolda20@gmail.com, ORCID: 0000-0001-2345-6789

Date Received: October 12, 2020

Date Accepted: December 8, 2020

To cite this document

Xiong, Y., Okorie, C., Ezeoke, G., (2020) Enhancing distribution network performance: a quantitative approach to developing a distribution strategy model. Journal of Management, Marketing and Logistics (JMML), V.7(4), p.160-182.

Permanent link to this document: $h$ htp://doi.org/10.17261/Pressacademia.2020.1331

Copyright: Published by PressAcademia and limited licensed re-use rights only.

\section{ABSTRACT}

Purpose- This paper examines distribution network and distribution strategy choice problem in the presence of uncertain demands. The authors discuss the implications of cost and capacity-utilisation in locating centralised or decentralised distribution centres, which are inherently associated with different distribution strategies.

Methodology- A case study approach is adopted, and several scenarios for distribution network and distribution strategy are designed, thus enabling us to perform in-depth analysis using mathematical modelling and simulation techniques. Based on the data from a real case study company, herein referred to as 'Corporation A', five typical scenarios are designed to represent different combinations of distribution networks and distribution strategies. The five scenarios are mathematically simulated to evaluate their costs and capacity-utilisations. A distribution strategy model (DSM) is then developed accordingly to support decision making for enhancing distribution performance.

Findings- The results show the potential of the developed distribution strategy model (DSM) in supporting consistent maximisation of distribution operations despite uncertainties in demands in a dynamic market environment, and hence lowering inventory and transportation costs. Whilst findings show the importance of using numerical approach in obtaining an optimum location for distribution centres, the study eventually revealed the necessary need to inject adequate level of informed local knowledge based on experience into decision making. Attributes such as costs, labour productivity, policy government, proximity to markets and suppliers are crucial in making the informed decision necessary for an optimum distribution facility location.

Conclusion- Uncertainties in demand put huge pressure on distribution-networks, with consequent significant costs and service implications. In search for solution to complex distribution problems, deploying a widened array of scenarios for scrutiny is necessary in reaching a robust and optimized solution. Given volatility in the contemporary supply chain, there are both theoretical and practical needs to actively consider, reconsider or re-design various distribution network for improved performance.

Keywords: Distribution network design, distribution strategy, risk-pooling, milk run shipment, quantitative approach JEL Codes: L91, L99, R41

\section{INTRODUCTION}

In recent decades, the trend of demand uncertainties has put more and more pressure on distribution-networks of supply chains, with consequent significant cost and service implications, thus necessitating that firms optimise distribution performances. Inventory cost is one of the 'Key Performance Indictors' (KPI) that influences decision-making in supply chains (Beuthe and Bouffioux, 2008). Minimisation of inventory, which has cost and service implications, is achievable by high-efficient management 
and operation (Slack et al., 2010). Cost saving is not only generated from inventory management, but also from the development of different distribution operation networks. As a result, changes in distribution network cause variations in cost, inventory and vehicle utilisation, which as widely acknowledged (Bowersox et al., 2007 ; Simchi-Levi et al., 2009 ; Crandall et al., 2010), are real challenges to many firms.

In this study, the implications of cost and capacity-utilisation in locating centralised or decentralised distribution centres associated with different distribution strategies are discussed and assessed using quantitative approach. With the overarching goal of improving logistics performance, it begins by examining theories of distribution network, network-problems and then an assessment of their potential impacts. Subsequently, based on 'Corporation A' case study, mathematical models for five distribution scenarios are formulation. Using the simulation approach, the models are analysed in order to assess their potential impacts on distribution performance. Finally, a distribution strategy model is developed, presenting trade-off analysis of the 5 feasible scenarios, to facilitate the improvement of distribution network performance.

\section{LITERATURE REVIEW}

\subsection{Research Background}

As companies are continuously striving for ways to maintain their competitive advantage and core competence in the global marketplace, cost reduction and value creation are necessities in improving supply chain performance (Hoffmann and Kumar, 2010 ; Meepetchdee and Shah, 2007 ; Christopher, 2005 ; Christopher and Towill, 2000). The main drivers of supply chain performance is divided into logistics-related drivers (facilities, inventory and transportation) and cross-functional drivers (information, sourcing, and pricing) (Chopra and Meindl, 2010). An excellent network design and re-design enhances company's simplifying of processes, reducing costs and improving service level (Boyson et al., 2011). Admittedly, network design provides an effective approach to balance supply, demand and simplification of cost and service structures (Boyson et al., 2011). As a result, value can be generated mainly by cost minimisation and profit maximisation in network design (Jung et al., 2004 ; Cohen and Moon, 1990 ; Tsiakis et al., 2001 ; Cohen and Lee, 1989 ; Gjerdrum et al., 2001). It is important therefore, to examine the impacts of the different distribution networks.

\subsection{The Impacts of Decentralised and Centralised Distribution with Risk-Pooling Application}

Decentralised systems are known to comprise of a collection of warehouses in the distribution network. As decentralised manufacturers' warehousing systems are closer to customers, there is the tendency for higher volume of inventory in each of the manufacturers' warehouses (Chopra and Meindl, 2010). Such decentralised warehousing systems are largely operated on the basis of direct shipment and milk run. The direct shipment strategy is adopted when goods must be shipped in isolated manner directly from warehouses or factories to customers. Many companies apply long-range direct shipping resulting in cost inefficiency, since there is excessive use of less than truckload (LTL) model of transportation (Caputo et al., 2005). These trends in high transportation costs are caused by extended distances and disaggregate shipments. It is economical to ship directly from plant to retailers if a shipment is full truckload (FTL) (Du et al., 2007). Milk run shipment is widely recognised by CSCMP (2010), Du et al. (2007), Bowersox et al. (2007), and Caputo and Mininno (1996). In milk run application, a vehicle leaves transportation depot (TD) to suppliers with empty truckload (ETL). It picks up goods with LTL, and then it leaves the suppliers to other suppliers on its' goods consolidation journey. When goods are collected with FTL, the vehicle leaves final supplier to different customers, dropping relevant rates of designated goods. When the vehicle completes delivery of goods, it returns to TD with ETL. This offers effective approach to achieving integrated lean logistics strategy, which as reiterated by Bowersox et al. (2007) supports the reduction of excessive transportation cost. The capacity to reduce transportation costs through milk run shipments is largely due to consolidation which offsets the use of small lot transportation (Brar and Saini, 2011).

Manufacturers and other upstream suppliers give centralised distribution system a great deal of consideration. In an absolutely centralised inventory system, a single central warehouse fulfils all the demands of various stores (Lee and Jeong, 2009). Inventory serves to confront uncertainties in demands from a large number of customers, thus centralised systems can minimise the safety stock thereby reducing inventory holding cost (Gerchak and Gupta, 1991). For this reason the risk-pooling strategy, which is concerned with aggregation of demand, can lower the safety stock required to achieve set customer service level (Wisner et al., 2012). To assess the extent of risk-pooling effect, the coefficient of variation (CoV) is used to measure demand variability (Cachon and Terwiesch, 2009). The higher the CoV, the greater the benefit received from the centralised system, i.e., greater the benefit from risk-pooling (Simchi-Levi et al., 2009). In addition, applying risk-pooling in a transportation network can cause reduced fleet size and number of staff, while increasing utilisation rate in vehicle movements (Hall, 2004). Fritzsche (2012) presented an inventory policy-pooling model, which supports the reduction of total costs and improvement in operational stock planning. 
Therefore, applying the risk-pooling strategy can lower the inventory stock in centralised warehousing system. There two main distribution networks attributed to the centralised system, namely - 1) all shipments via DC with inventory storage and 2) shipping via DC using milk run. In the first type shipment, suppliers transfer goods to DC, and then from the DC forward shipments to each buyer's location (Chopra and Meindl, 2010). The reduction of transportation costs is based on aggregation of goods through distribution channel in FTL (Apte and Viswanathan, 2000). Each supplier requires a large shipment to the DC that contains products for all sites (buyers) served by the DC, thus it can achieve economies of scale in transportation to a point near to the final destination (Chopra and Meindl, 2010). In the second shipment approach, each supplier's goods are shipped to DC for consolidation, and then delivery to final customers is made using the milk run system. This type of system, shipping via DC using milk run, chooses from two different shipping methods, namely FTL and LTL (Carinic, 1999). The FTL capacity can result in lowest cost. In LTL shipping, only a fraction of the entire truck capacity is hired and the cost is proportional to the transported amount with specific fees depending on weight ranges and the destination zone (Caputo et al., 2006).

\subsection{The Problem of Network Cost}

A profound aspect of distribution network is the assessment of the relationship between total distance and transportation costs in order to evaluate network costs. The achievement of minimum total cost is driven by cost-to-cost trade-offs, which is increasingly dependent on total inventory and transportation costs (Bowersox et al., 2007). While transportation cost rises along with increasing distances travelled by a vehicle, increase in weight of loads benefits from economies of scale and reduction of cost per pound (Bowersox et al., 2007). On the other hand, as the number of warehouses and other logistical facilities increases, transportation cost reduces, though inventory and facilities costs may increase (Coyle et al., 2009). It is pertinent however to observe that there is the tendency to accumulate high aggregated transportation costs with excess number of facilities. Therefore, the minimal transportation cost is achievable between two aspects of distance travelled and number of facilities (Chopra and Meindl, 2010). The inventory costs aspect are mainly categorised into carrying cost, order and setup cost and stockout costs (Swink et al., 2011). Carrying costs encompasses the expenses in a warehouse, costs of special storage requirements and opportunity cost of the investments, damage, theft, insurance and taxes (Silver et al., 1998). Additionally, inventory costs become higher by increasing the number of facilities.

\subsection{Vehicle Routing Problem}

Another distribution network challenge is vehicle routing, which is influenced by the relationship between distance, route and vehicle capacity. Geographic information system (GIS) as a computer-based tool is applied for mapping and analysing spatial data which provides effective method for network analysis and route planning (WestminsterCollege, 2012). GIS not only achieves cost savings and increased efficiency, but also supports better decision-making, improved communication, better geographic recordkeeping and management (Esri, 2012). Truckload capacity is a critical parameter for calculating route distance, thus vehicle routing problem (VRP) identification and analysis, leading to resolution of the problem between truckload capacity and distance for the purpose of improving efficiency and meeting customers' requirements (Federgruen and Simchi-Levi, 1995). For the sake of vehicle travelled distance based on truckload capacity, capacitated vehicle routing problem (CVRP) provides effective algorithm and method for assessing the interaction between capacity and distribution route (Augerat et al., 1998). As further explained, Augerat et al. (1998) held that CVRP presents the challenge of finding routes for different vehicles, with minimum total cost, and each customer belonging to exactly one route, each route containing designated depots and each delivery to customers not exceeding the given vehicle capacity. Furthermore, freight transport creates a major logistical challenge, concerning acquisition of backloads and the empty runs for returning vehicles and also geographical imbalances in traffic flow, short haul lengths, scheduling constraints and the incompatibility of vehicles and loads (McKinnon and Ge, 2006).

\subsection{Network Location Problem}

A good warehousing site selection which offers strategic advantages is confronted with four main issues for consideration, namely, physical infrastructure, proximity to suppliers and customers, political and tax issues and international trade conditions (Thai and Grewal, 2005 ; Shang et al., 2009). Thai and Grewal (2005) developed a conceptual framework for site selection. General geographical area identification, alternative sites and gateways seaports/airports identification, and specific site selection are the main options of site location. Considering geographical area identification, the Centre of Gravity (CoG) principle is defined as an imaginary point where all the weights of an object can be considered to be concentrated (Thai and Grewal, 2005).

Although a considerable number of studies have been conducted focusing on the impacts and decisions on individual components such as transportation, inventory, location, routing and scheduling, truckload capacity, rather less attention has 
been paid to the overall impacts of logistics network and distribution strategy on performance indicators such as storage cost, inventory cost, transportation cost, travel distance, inventory utilisation and vehicle utilisation in the presence of demand uncertainty, which will be examined in this paper. For the case study company examined in this paper, the main problem was that of high logistics costs in rendering services.

\section{DATA AND METHODOLOGY}

\subsection{Problem Formulation}

The distribution network and distribution strategy choice problem in our context mainly concerns selecting the location of central distribution centre $(C D C)$ and the inventory management and transportation arrangement between factories and CDC, and between CDC and regional distribution centres (RDCs). We adopt a case study approach and design several scenarios for distribution network and distribution strategy options, which enable us to perform in-depth analysis through mathematical modelling and simulation techniques.

Case study research strategy enables the investigation of a particular contemporary phenomenon within its real life context using multiple sources of evidence (Robson, 2002). Researchers gain enhanced understanding of the context and processes being investigated in a specific case study (Eisenhardt and Graebner, 2007). To examine distribution network problems and assess their potential impacts, this paper takes the quantitative approach, deploying case-study-supplied numerical data, which were analysed using Excel facilitated simulation. Simulation, which provides techniques to imitate the operation of a real-world process or system over time (Banks, 1998), provided the needed approach to reaching possible solutions in this study. As widely acknowledged, spreadsheet simulations are implemented by devising a simulation table that produces a method for tracking a system's state over time which enables the generation of corresponding mathematical models for possible solutions (Matko et al., 1992 ; Valten, 2009); Bank., 2010).

\subsection{The Scope and Process}

This section shows the scope of the simulation and illustrates the application of Input-and-Output system in simulation using Figure-1 and Table-1. Then, the algorithms for centralised and decentralised inventory cost and utilisation are developed. Subsequently, simulation of warehouse site location is carried out. Finally, algorithms for transportation cost and vehicle utilisation in 5 scenarios are developed.

Fig. 1: Flow of Simulation and Assessment of 5 Feasible Scenarios

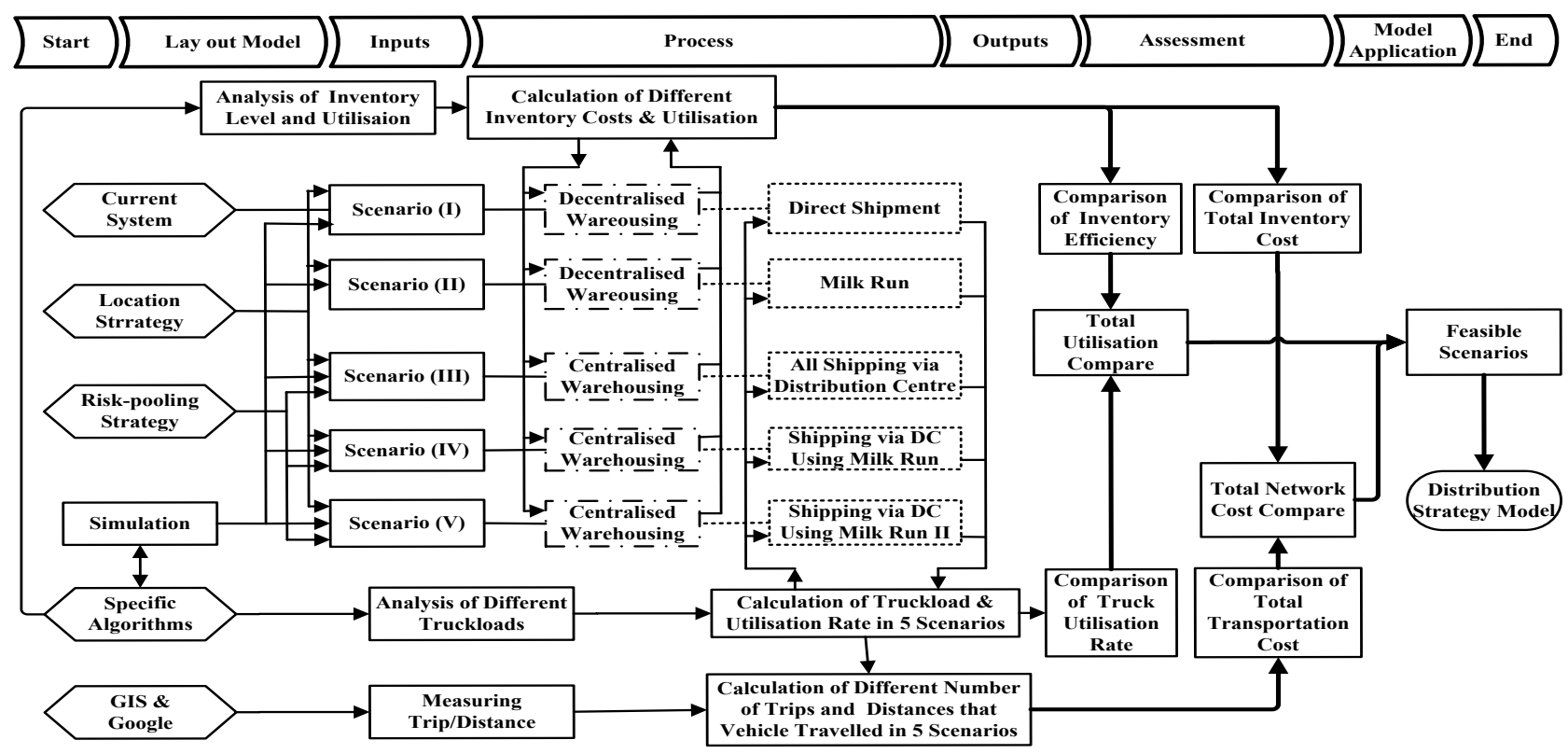


Fig. 1 shows the simulation approach taken in developing the 5 distribution scenarios. The scenarios comprise of two categorises: decentralised- scenario (I) and (II); and centralised system-scenario (III), (IV), and (V). The study commenced with the development of mathematical models (see Appendix-A) of the 5 scenarios which consist of parameters of inventory and transportation. In the process, the primary data were inputted in the algorithms using spreedsheet and GIS tools for distance measurement and then the simulation process was run. Subsequently, each of the 5 scenarios was simulated using the same process and results were collected on completion. For the decentralised scenarios (I) and (II), the inventory simulation algorithm and data were the same; however, both scenarios differ in transportation variables. Concerning decision for appropriate new site location in centralised distribution system, computation based on CDC coordinates for scenarios (III), (IV), and (V) was carried out. Given this approach, the algorithms for inventory related-operations were thus different in scenarios (III), (IV), and (V). While the simulation process for inventory remained the same in scenarios (III), (IV), and (V), it was different for transportation, given that the different scenarios deployed different parameters. Simulation generated-data were subjected to further analysis as enabled by Excel tool so as to assess and contrast the cost and utilisation (i.e. inventory and transportation) between the five scenarios. These culminated to the development of a distribution strategy model, applicable for different attributes by trade-off analysis in order to enable decision-making to improve distribution network logistics performance.

\subsection{Identification of Mathematical Model in the Five Scenarios}

Fig. (2-6) show the features of the 5 scenarios upon which simulations were run using data supplied by Corporation A, while the discussion that follows, develops algorithms of inventory, transportation costs and their utilisation.

Fig. 2: Scenario (I) Decentralised Warehouse and Direct Shipment

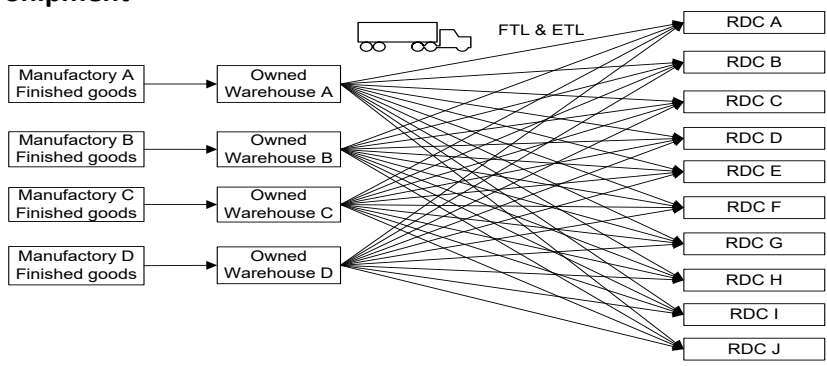

Fig. 3: Scenario (II) Decentralised Warehouse + Milk Run Shipment

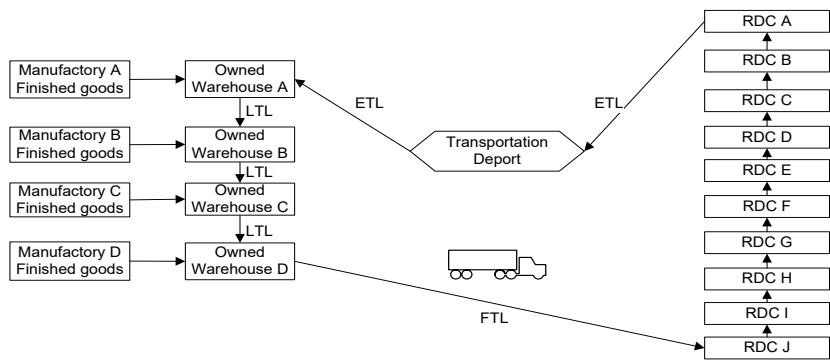

Fig. 4: Scenario (III) Centralised Warehouse + All Shipments via Distribution Centre

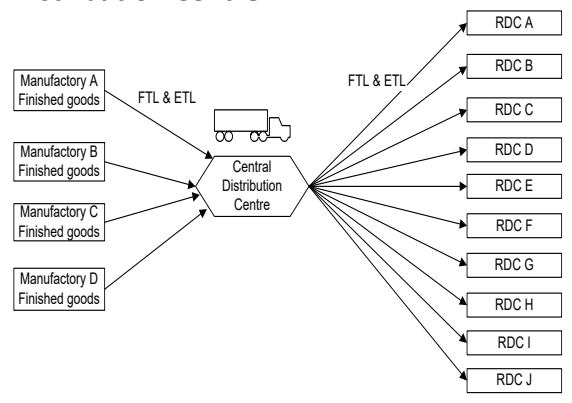

Fig. 5: Scenario (IV) Centralised Warehouse + Shipping via DC Using Milk Run

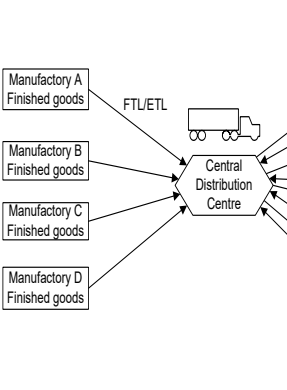

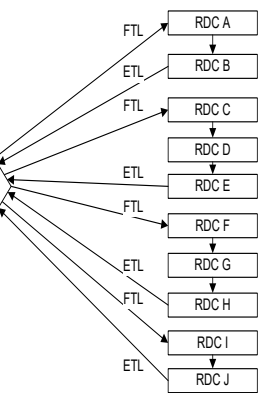

Fig. 6: Scenario (V) Centralised Warehouse + Shipping via DC Using Milk Run (2)

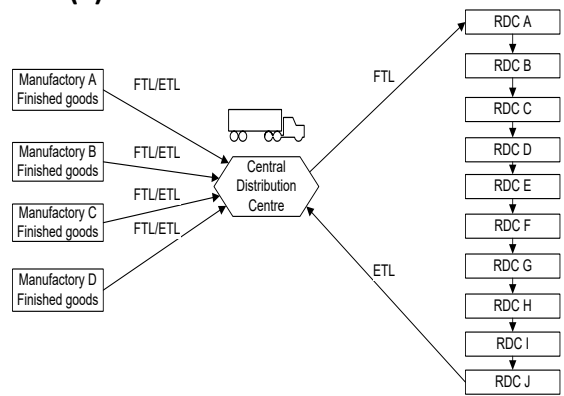


Table 1: The Nomenclatures for Algorithms in 5 Scenarios

$\begin{array}{cl}\sigma_{D}^{C} & \text { Standard deviation of monthly demand at CDC } \\ L & \text { Replenishment lead-time: Scenario (III), (IV), and } \\ & (\mathrm{V}) \\ x_{i} & \text { Quantity of demands in each warehouse ( } i=1,2, \\ & \ldots, I) \\ C_{i} \text { or } & \text { The coordinate of Warehouse } i \text { or RDC } j \\ C_{j} & \\ Z & \text { Service factor } \\ Q & \text { Order quantity from all RDCs } J \text { (Scenario III-V) } \\ K & \text { Fixed ordering cost (Scenario III-V) } \\ H & \text { Inventory holding cost at warehouse/CDC } \\ I & \text { Total number of warehouses/CDC } \\ J & \text { Total number of RDCs } \\ I & \text { The warehouse } i(i=1,2, . ., I) \\ J & \text { The RDC } j(j=1,2, \ldots, J) \\ f & \text { Freight rate (tonne-kilometre) }\end{array}$
$o, p, q, r \quad$ Number of RDCs called by trucks in one trip [in scenario (IV) (where, $o+p+q+r=J)]$
$m \quad$ Maximum truck carrying capacity
n Integer number
$d_{i}^{M R} \quad$ Distance (from factory to RDCs) in scenario (I)
$d_{2} \quad$ Distance in scenario (II)
$d_{i}^{3 M C} \quad$ Distance (from factory to $\mathrm{CDC}$ ) per return-trip in scenario (III)
$d_{j}^{3 C R} \quad$ Distance (from CDC to RDCs) per return-trip in scenario (III)
$d_{i}^{4 M C} \quad$ Distance (from factory to $\mathrm{CDC}$ ) per return-trip in scenario (IV)
$d_{i}^{4 C R} \quad$ Distance (from CDC to RDCs) per return-trip in scenario (IV)
$d_{i}^{5 M C} \quad$ Distance (from factory to $\mathrm{CDC}$ ) per return-trip in scenario (V)
$d^{5 C R} \quad$ Distance (from $\mathrm{CDC}$ to $\mathrm{RDC}$ ) per return-trip in scenario (V)

Note: The distance for are $\boldsymbol{d}_{i}^{3 M C}, \boldsymbol{d}_{i}^{4 M C}, \boldsymbol{d}_{i}^{5 M C}$ the same.

Using algorithms in table 1 the five scenarios [Scenario (I) Decentralised Warehouse and Direct Shipment; Scenario (II) Decentralised Warehouse + Milk Run Shipment; Scenario (III) Centralised Warehouse + All shipments via Distribution Centre; Scenario (IV) Centralised Warehouse + Shipping via DC Using Multi-Route Milk Run; Scenario (V) Centralised Warehouse + Shipping via DC with single-route Milk] presented in Fig. 2-6 are developed and simulated.

In scenario (I), the decentralised warehouses (with total number I) are owned and operated by the factories of Corporation A. The demand in warehouse $\left(x_{i}\right)$ for supplies of different types of products is equally split among all RDCs (with total number $J$ ). Each factory delivers equal amount of goods to RDCs by direct shipment through $d_{i}^{M R}$ kilometres.

For the scenario (II), note that the algorithms and data for inventory cost and utilisation are the same as in scenario (I), thus we hereby concentrate on developing algorithms for transportation cost and capacity utilisation. Fig. 3 displayed the milk-run distribution network. A truck with ETL travels from TD to warehouse (i), picking up goods from each warehouse proportionally at a rate $\left(\frac{x_{i} \cdot m}{\sum_{i=1}^{l} x_{i}}\right)$. Then, after the truck collects designated rates of goods across all warehouses $(i=1,2, \ldots, l)$, with the FTL $(m)$, it leaves the final warehouse $i$. Afterwards, the truck drops goods to $(J)$ RDCs at an average rate and returns to TD with ETL.

In scenario (III), algorithms to assess a distribution network type of centralised warehouse with all shipments via DC are developed. As shown in Fig.4, goods are aggregated in the CDC ( $i=1)$, and then respectively dispatched to RDCs. The location determination of $C D C$ is dependent on the centre of gravity model. Centralised warehouse implies the implementation of riskpooling strategy. Goods in CDC are equally delivered to $J$ (RDCs) by direct shipments.

Refer to the Fig. 5 (scenario IV) which shows that finished goods are aggregated in CDC/warehouse (i) from 4 factories at the beginning of operation, and then distributed to each RDC $(j)$ by the multi-route milk-run network operation. The warehouse and 1st transportation segment operation is same as the scenario (III), while the 2nd transportation segment is dependent on the multi-route milk run. Total $\operatorname{RDCs}(J)$ are split into 4 different routes, namely $o, p, q$, and $r$ delivery routes.

Fig. 6 displays a type of network for scenario (V) which is the combination of scenario (II) and (III). Note that the distance of the 2nd transportation segment $\left(d^{5 C R}\right)$, is measured by GIS. 
Further details on the development of algorithms and equations in relation to inventory, freight, and vehicle utilisation for scenarios (I-V) can be found in Appendix A.

\section{FINDINGS AND DISCUSSIONS}

\subsection{Results and Discussions}

Given complexities, a representative one month's operation sample data and developed related algorithms are used to analyse occurring variations and eventually discuss feasible scenarios for establishing a model for distribution strategy which will be applied in different situations to enhance logistics performance. For the distribution network understudied, Corporation A, mills are located in the south coast of Guangdong province of China, from where factories deliver goods to 10 RDCs within the province.

The annual demand volume supplied is shown in Appendix-B, lead-time $(L)$ is 1 month, fixed cost $(k)$ is $f 20,000$, one month

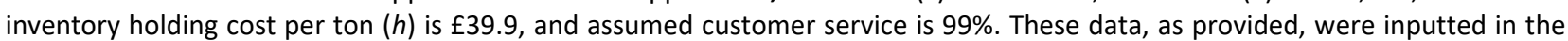
developed algorithms so as to assess the impacts on annual cost and utilisation of inventory and transportation. The distribution network examined by developing different simulation scenarios relies more on the location and current distribution network of Corporation A is as shown in scenario (I) (see Fig. 2).

\section{Fig. 7: The Location of Distribution Sites}

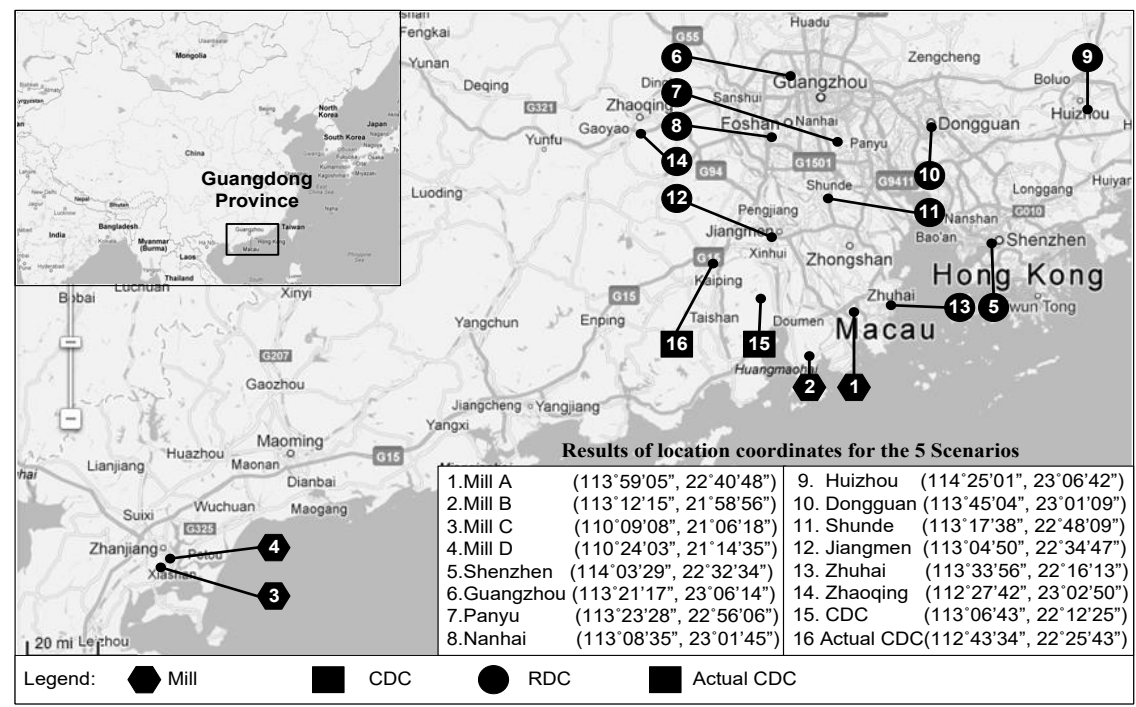

Fig. 7 displays the locations of the distribution facilities, and also the results of the location coordinates for the five simulated scenarios. Analysis showed that the resultant and optimum simulated location for centralised distribution centre (CDC)/transport depot (TD) sites is in reality in a mountainous and forest region, which makes the site inappropriate for feasible practical use. When a situation, such as this is encountered, we join authors, e.g. (Ballou, 2004 ; Thai and Grewal, 2005 ; Shang et al., 2009 ; Slack et al., 2010), to call for the ingestion of adequate level of subjectivity based on informed and knowledgeable decisions. For this reason, it is proposed that the CDC be located as close in proximity as possible to the Centre of Gravity (CoG), considering convenience and other business features. While making business location decisions, factors for consideration include proximity to markets and suppliers, costs, labour productivity and attitudes of government (Heizer and Render, 2001). In this context, we therefore propose that the Kaiping (approximate $112^{\circ} 43^{\prime} 34^{\prime \prime} \mathrm{E}, 22^{\circ} 25^{\prime} 43^{\prime \prime} \mathrm{N}$ ) site presents both the optimum and practicable location for the CDC/TD. This is supported by three reasons; (1) proximity with the CoG determined location, (2). Greater accessibility to the highways (3). Cost saving potential.

\subsection{Risk-Pooling Effect}

Having discussed the optimum and feasible location for the $C D C$, attention is hereby given to examining the consequent riskpooling strategy. In assessing the impact of risk-pooling strategy on the warehouse/CDC, it is important to evaluate the 
coefficient of variation (CoV) for products' storage costs. Thus, for four products of Corporation A, the CoVs in centralised and decentralised warehouses are computed.

Fig. 8: Changes of Coefficient of Variance for 4 Types of Products between Decentralised and Centralised Warehouse Annually

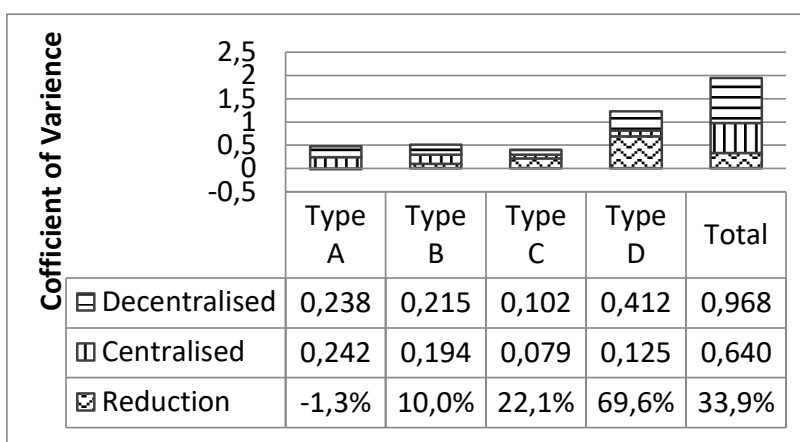

Fig. 9: Changes of Storage Cost for 4 types of Goods between Decentralised and Centralised Warehouse Annually

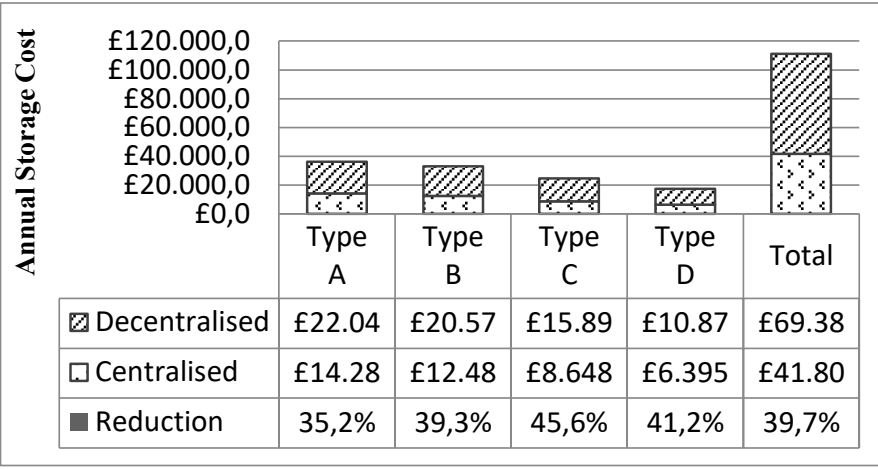

Fig. 8 shows the CoV results for the four types of products, while Fig. 9 correspondingly presents the cost variations for the products in centralised and decentralised systems. The CoV is directly influenced by variations in the volume of products requiring storage. Results reveal the trend that demands for storage is largely lower in the centralised than in the decentralised warehouse network. Thus, conforming the view in Simchi-Levi et al. (2009) that the higher CoV (as herein is the case for the decentralised), the greater the benefit obtained from centralised system. That means having greater benefit from risk-pooling', although this is slightly different for type A goods where the resultant $-1.3 \%$ CoV puts decentralised strategy as being advantageous. The different volumes of demand for the 4 categories of goods are the cause of different total costs and utilisation in the 5 scenarios.

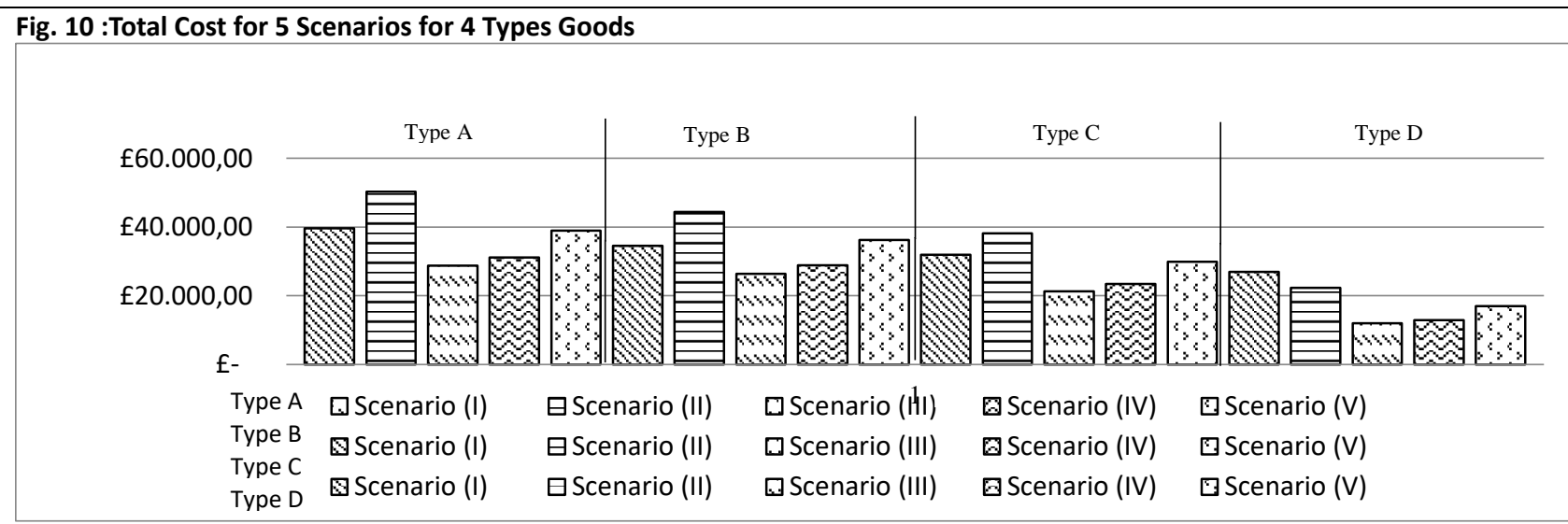

Note: Type A, B, C, and D represents different volume of demands, 8135 tons, 7751tons, 6790tons, and 3502tons respectively, (see appendix-B) 
Fig. 11: Inventory and Vehicle Utilisation for 5 Scenarios for 4 Types Goods

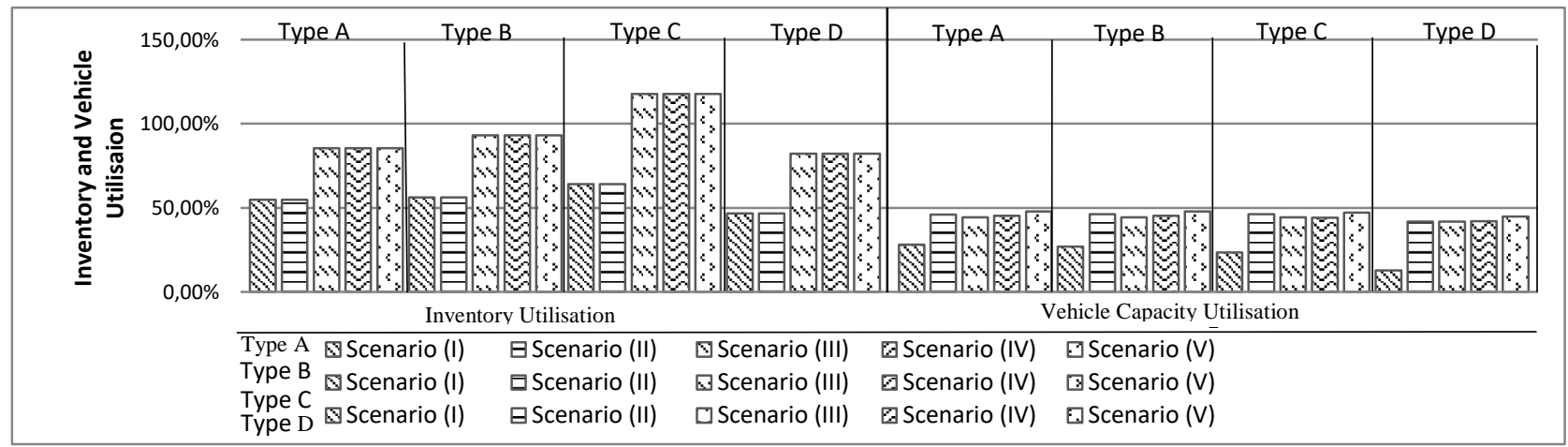

The different types of goods are fundamentally indications for different volumes of goods and not necessarily about the features of the goods. Note that, Type A has the largest volume (1st vol.), followed by type B (2nd vol.), type C (3rd vol.) and type D (4th vol.) has the least volume. In Fig.10, it is shown that using a particular scenario (distribution network) in the handling of a category of goods produces different cost implications. This scenario and cost relationship is subject to variations in the volume of category $A, B$, and $C$ goods for the 5 scenarios. As indicated, the different types of goods have different volumes (tons); $A$ (8135), B (7751), C (6790) and D (3502), which thus affect the costs level for any of the distribution network. The cost was found to be on a corresponding decrease as volume decreases for the different categories of goods, in other words, there was a general trend of the higher the volume, the higher the cost for all the different scenarios. However, the greater reduction in the volume of type D, resulted in scenario (II), see Fig. 3, being considered as a preferable option to scenario (I) for cost reduction. As a result, scenario (I) which is the current distribution network for Corporation A is of more cost benefit with higher volume of goods, whereas the scenario (II) is of cost benefit with lower volumes. For theoretical benefit, we emphases that for a given distribution network, the variations in the volume of goods have substantial cost implications that demands closer scrutiny. On the other hand, changes in volume of goods do not only have effect on total cost, but also on inventory and vehicle utilisation, as shown in Fig 11. Of all the types of goods considered, (i.e. A, B, C and D), the type C goods (6790tons) were found to have the highest level of inventory utilisation, when compared to those of other types with higher or lower inventory volumes. This trend therefore, reveals that utilisation of inventory is at its peak when inventory is neither very higher nor very low. Additionally, vehicle capacity utilisation for the 4 types of goods in scenarios (II), (III), (IV), and (V) is approximately $45 \%$ while vehicle capacity utilisation for scenario (I), which is the current operated distribution network for Corporation A was found to be lesser. This outcome is understood in the light that the direct shipment of scenario (I) results in lower vehicle-goods consolidation, whereas using the other simulated scenarios presents the potential of achieving higher vehicle-goods consolidation. Thus, the distribution network re-engineering capacity presented by the simulation approach avails firms the opportunity to re-consider and re-design their network operations to achieve vehicle-goods aggregation, leading to higher vehicle capacity utilisation.

\subsection{Evaluation of Total Distribution Cost, Utilisation and Related Issues}

Fig. 12 shows the different performances for transportation, inventory and total cost in the 5 scenarios. On the other hand, Fig. 13 and Fig. 14 present the inventory and vehicle utilisation, and total distance respectively for the 5 scenarios. The discussions that follow consider all the features of the three figures in an integrated manner. 
Fig. 12: Distribution Cost

\begin{tabular}{|c|c|c|c|c|c|}
\hline \multirow{6}{*}{$\begin{array}{c}£ 300.000,00 \\
£ 250.000,00 \\
£ 200.000,00 \\
£ 150.000,00 \\
£ 100.000,00 \\
£ 50.000,00 \\
£-\end{array}$} & & & & & \\
\hline & 20 & 20 & & & \multirow[b]{3}{*}{$\infty$} \\
\hline & 20 & 26 & & & \\
\hline & 20 & 20 & \multirow{2}{*}{$\infty$} & & \\
\hline & $\infty$ & $2 \ldots$ & & & $\infty$ \\
\hline & Scenario (I) & Soonorio (II & Somir (IJI) & & Sororia \\
\hline & & & & & \\
\hline 口 Inventory Cost & $£ 149.385,18$ & $£ 149.385,18$ & $£ 61.809,43$ & $£ 61.809,43$ & $£ 61.809,43$ \\
\hline (Transportation Cost & $£ 78.093,70$ & $£ 100.047,75$ & $£ 46.529,17$ & $£ 54.402,57$ & $£ 80.274,88$ \\
\hline QTotal Cost & $£ 227.478,88$ & $£ 249.432,93$ & $£ 108.338,59$ & $£ 116.212,00$ & $£ 142.084,30$ \\
\hline
\end{tabular}

Fig. 13: Inventory Utilisation and Vehicle Utilisation

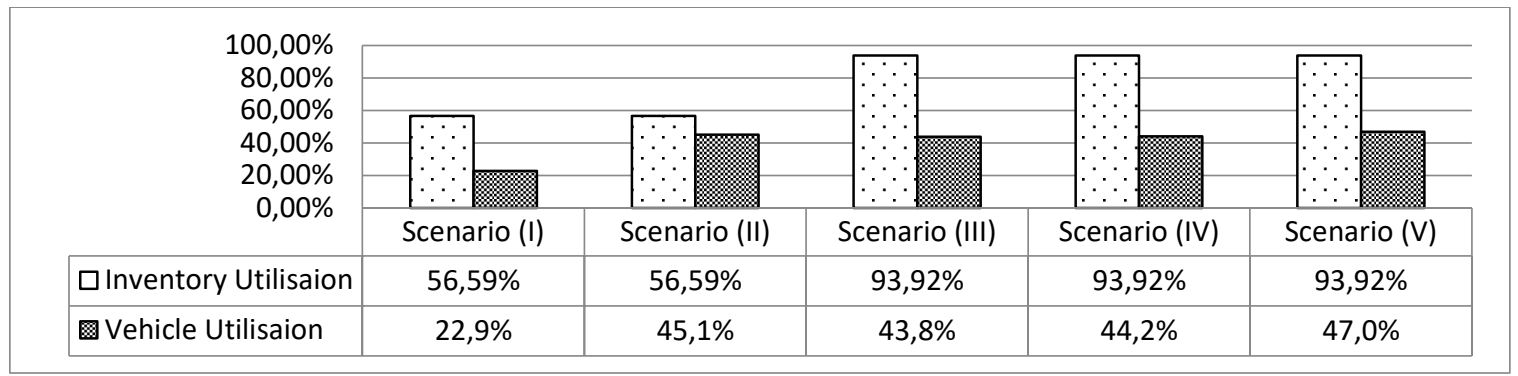

Fig. 14: Transportation Distance

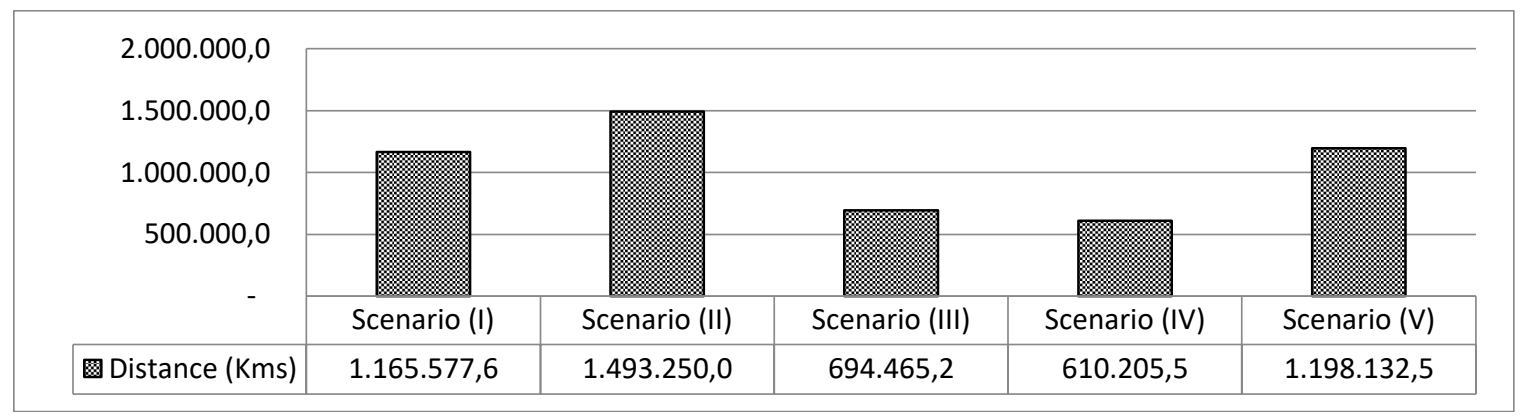

Scenario (1) has the 2 nd highest total costs of all the 5 scenarios. It incurs higher transportation cost $(£ 78,093.70)$, due to longrange direct shipping (i.e.1,165,577.6 Km) and excessive LTL (less than truck load) model of transportation. On the other hand, it suffers from higher inventory cost $(£ 149,385.18)$, because of the decentralised warehouse system. Scenario (II) shows the highest total costs. The inventory cost is same as scenario (I), $f 149,385.18$, however, its' transportation cost is the highest (i.e. $£ 100,047.75)$, given that it covers about $1,496,250 \mathrm{Km}$ in the delivery of goods to RDCs by milk-run shipment. On the brighter side, further analysis of scenario (II) revealed that the vehicle capacity utilisation increased from $22.9 \%$ to $45.1 \%$ of that of scenario (I). Results of Scenario (III), centralised warehouse plus all shipment via DC, yielded the lowest inventory and transportation costs, however it resulted in a lower vehicle capacity utilisation. All goods are aggregated in CDC across 4 factories with the application of 'risk-pooling' strategy, resulting in inventory cost reduction to $f 61,809.4$. This reduction in inventory cost is achieved by 'consolidating products with random demands into one location', thus taking advantage of economies of scale (Eppen, 1979 ; Cherikh, 2000). In addition, the scenario achieved the lowest transportation cost ( $₫ 46,529.17)$, although its vehicle utilisation, $43.85 \%$ is lower in comparison with other scenarios. Amongst the five scenarios, scenario (IV), centralised warehouse plus shipping via DC using milk-run, possesses the best logistics performance attributes with the inventory and transportation costs. The scenario produced the shortest distance for the distribution of goods, which implies the possibility for quick-response. Scenario (V) network design was slightly different from the scenario (IV), with respect to vehicle routing. Consequently, inventory 
cost remained the same for the scenarios $(£ 61,809.43)$, while the scenario $(V)$ transportation cost $(f 80,274.88)$ was quite higher than other centralised distribution scenario (III, IV). It produced the highest vehicle utilisation performance (47\%).

One of the noteworthy outcomes is that the application of risk-pooling strategy, aggregation and consolidation, in centralised warehousing generated a significant inventory and transportation cost savings. Also, given the capacity for consolidation, higher vehicle capacity utilisation is attributed to milk-run shipment, although the distance for this type of distribution network is usually longer.

Table 2: Ranking of Logistics Performance for the 5 Scenarios

\begin{tabular}{|c|c|c|c|c|c|c|c|c|}
\hline & $\begin{array}{c}\text { Storage } \\
\text { Cost }\end{array}$ & $\begin{array}{l}\text { Fixed } \\
\text { Cost }\end{array}$ & $\begin{array}{c}\text { Inventory } \\
\text { Cost }\end{array}$ & $\begin{array}{l}\text { Inventory } \\
\text { Utilisation }\end{array}$ & Distance & $\begin{array}{c}\text { Transportation } \\
\text { Cost }\end{array}$ & $\begin{array}{c}\text { Vehicle } \\
\text { Utilisation }\end{array}$ & $\begin{array}{c}\text { Total Logistics } \\
\text { Performance }\end{array}$ \\
\hline Scenario (I) & 2 & 2 & 2 & 2 & 3 & 3 & 5 & 19 \\
\hline Scenario (II) & 2 & 2 & 2 & 2 & 5 & 5 & 2 & 20 \\
\hline Scenario (III) & 1 & 1 & 1 & 1 & 2 & 1 & 4 & 11 \\
\hline Scenario (V) & 1 & 1 & 1 & 1 & 4 & 4 & 1 & 13 \\
\hline
\end{tabular}

Key: [1:Best, 5:Worst]

Given the evaluation of total distribution cost, utilisation, and related issues, table 2 shows the ranking of the different logistics performances for the 5 scenarios. The performances of decentralised scenarios (I) and (II) are very similar, whereas the centralised scenarios (III), (IV), and (V) have related performance trend. Analysis of the results shows scenario (IV) as having potential of being the optimum distribution network strategy for Corporation A, particularly for the reasons of lower inventory and transportation costs, higher inventory utilisation and shorter routing distance. Findings therefore reiterate the view that the longer the distribution route, the higher the transportation cost.

\subsection{Trade-off Distribution Strategy Model Application}

On the basis of discussions, assessments and comparisons in this study, and fundamentally the outcomes and findings from table 2, a trade-off distribution strategy model (Fig. 15) has been developed. To support making a suitable choice of distribution network scenario(s), the model relies on table 2, in determining the relative importance-ranking of the eight analysed attributes. Thus, the model shows the eight different attributes (in the quadrilaterals), representing eight features to achieving cost and/or service values. It presents decision-makers with a tool for trade-off analysis to enhance distribution logistics performance. Attributes of this model are shortest distance, lower cost for lot sizes, lowest total cost, highest logistics performance, lowest inventory cost, lowest transport cost, highest vehicle utilisation and highest inventory utilisation. Using this model, the different scenarios discussed can be examined and decision made for application to achieving one or more suitable attributes. 
Fig. 15: Trade-off Distribution Strategy Model

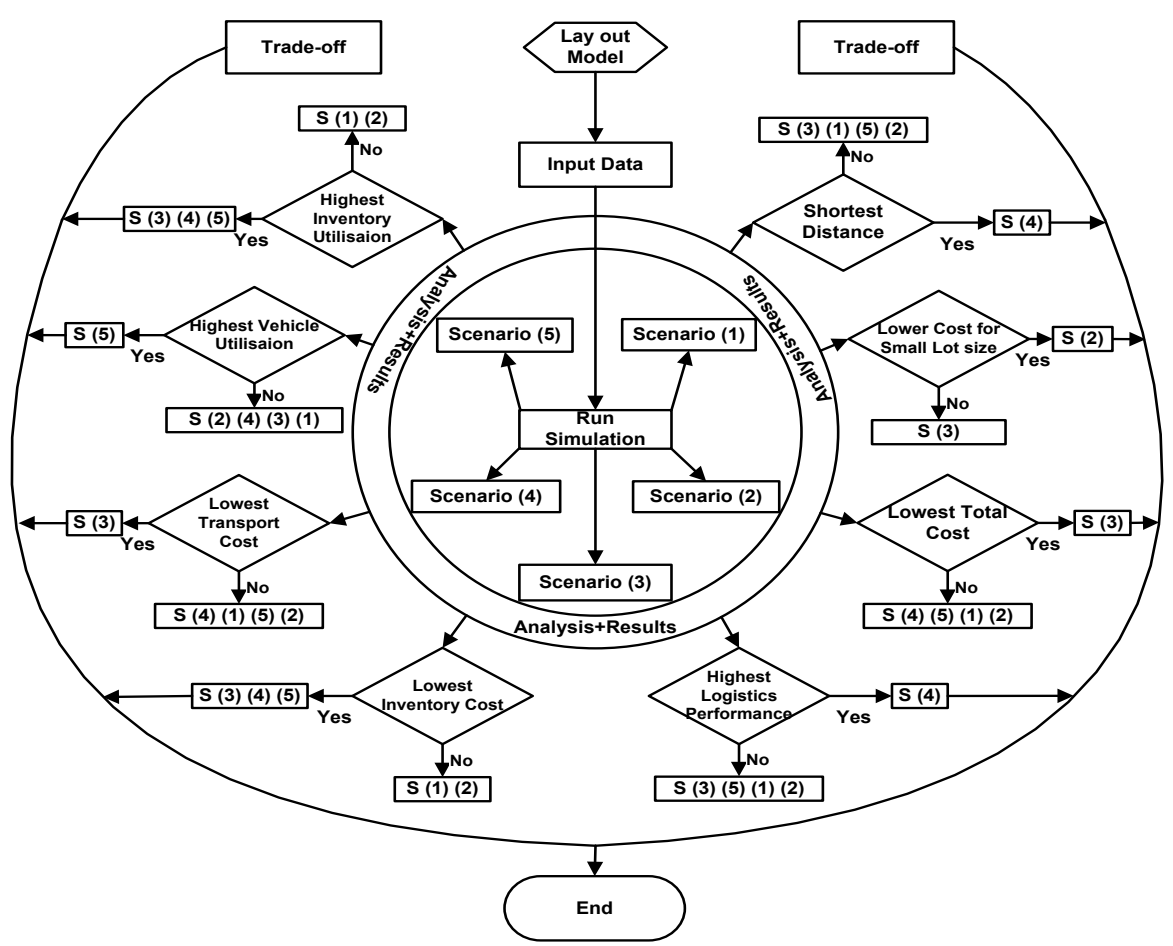

When the desire is to achieve quick-response to market, opinions by authors as Chopra and Meindl (2010) support the view that scenario (I), direct shipment, holds potentials that are worth consideration, particularly the capacity to handle high level of varieties, and the need to eliminate intermediate warehouses to achieve simplicity in operation and coordination. However, application of scenario (I) incurs high inventory and transportation costs, as shown by results in table 2 . In addition, it generates a lower vehicle utilisation due largely to the empty truck load (ETL) in backhaul. Scenario (II), milk-run enables a pattern of goods consolidation through calls to multiple pick-up sites, resulting in higher vehicle utilisation and delivery of transport cost-savings. Findings show that milk-run distribution network strategy favours the delivery of small lot sizes of goods. However, this decentralised distribution option might have higher inventory cost, because multiple warehouses, and sometimes may result to high total cost. Scenario (III), centralised distribution with all shipment via DC, can be more economical by the reason of consolidation in risk-pooling strategy. However, higher vehicle utilisation cannot be guaranteed. In a nutshell, as concerning costs, the scenario (III) achieves the lowest total cost, although its vehicle utilisation is not the best. Scenario (IV) centralised warehouse plus shipping via DC using milk-run, shows relatively low inventory and transportation costs. With part application of milk-run shipment, higher vehicle utilisation can be achieved than is the case for direct shipment. An integrated analysis of all distribution features reveals that this scenario produces the highest logistics performance. However, it may have increased coordination complexities. Scenario (V) centralised warehouse plus shipping via DC using milk-run (2), tends to be appropriate to achieving similar attributes as in the case for the scenario (IV). The routing for this type of milk-run shipment is improved, producing higher vehicle utilisation than those other four scenarios. One could however, anticipate goods coordination challenges within the DC.

\subsection{Distribution Strategy Model's (DSM) Areas of Application}

In addition to the manufacturing industry, the distribution strategy model will be relevant and applicable in firms of transport operators, supply chain solution specialists, third party logistics (3PLs), fourth party logistics (4PLs) and any other business sector with distribution interests. The model provides a tool to:

- Support the decision-making process of businesses in determining the most appropriate distribution network. 
- Consider, design, re-consider and re-design various distribution network scenarios as developed and implemented in section 3.2, Figs. 2-6 using simulation techniques.

- Optimise the utilisation of businesses' distribution resources, thus supporting profit maximisation.

- Stimulate more interest in key areas of supply chain re-engineering in the industry and theoretical domains.

\section{CONCLUSION}

The nature of distribution network design and its operations can have significant implications on the whole supply chain. The discussed case study (Corporation A) operated a decentralised distribution strategy that created high costs, thereby faced with the need for re-engineering of the supply chain and distribution operations. Supplied data were used to run different simulation scenarios and generated outputs were analysed for informed distribution network decisions. Scenario (I) presented the current distribution network of the company, while Scenario (IV) which yielded the total highest logistics performance presents the option of centralised warehouse plus shipping via DC using milk run. Scenario (III) (i.e. centralised warehouse plus all shipment via DC) has the potential for an economic output, given capacity for lower inventory and transportation cost; however, it could yield lower vehicle utilisation. Scenario (V), centralised warehouse plus shipping via DC using milk-run (2) combine the strengths of scenarios (II) and (III). Trade-off analysis, on which platform discussions were made in this paper, is deemed crucial when making decisions for a suitable and feasible distribution network strategy. Based on findings in relation to driving down costs while simultaneously increasing capacity utilisation, the proposed trade-off distribution model provides a tool to enable companies enhance distribution network and thus logistics performance. Results show that network design, transportation frequencies and inventory levels have significant impacts on the associated costs and performance of a particular distribution network, hence form integral parameters for consideration in strategy decisions. The distribution strategy model (DSM) is relevant in the manufacturing industry offering opportunities for cost-savings and efficient distribution operations as analysed in the case of Corporation A. However, the potential and applicability of the model extents to firms of transport operators, supply chain solution specialists, third party logistics (3PLs), fourth party logistics (4PLs) and any other business sector with distribution interests. The research limitation can be seen in the light that simulation led quantitative approach was primarily adopted in developing and discussing the different developed distribution scenarios. This approach could also have been supplemented by qualitative research means. To further test the model, firms in the discussed and related industries are invited to consider adopting findings in this paper and the distribution strategy model in the designing and re-designing of their distribution network, and share their experiences and implementation implications. The development of the distribution strategy model (DSM) has been based on data from the manufacturing sector's distribution operation. Experimentation attention will be focused on adapting and further testing the model in the business of common carriers and supply chain solution specialists.

\section{REFERENCES}

Apte, U. and Viswanathan, S. (2000) Effective Cross Docking for Improving Distribution Efficiencies. International Journal of Logistics Research and Applications, 3(3), 291-302. Doi.org/10.1080/713682769

Augerat, P., Belenguer, J. M., Benavent, E., Corberan, A. and Nadder, D. (1998) Separating Capacity Constraints in the Cvro Using Tabu Search. European Journal of Operational Research, 160(2-3), 546-557. DOI:10.1016/S0377-2217(97)00290-7

Ballou, R. (2004) Business Logistics/Supply Chain Management: Planning, Organizing, and Controlling the Supply Chain, New Jersey, Pearson Education.

Bank. J., C. I., J., Nelson, B., And Nicol, D. (2010) Discrete-Event System Simulation, London, Pearson.

Banks, J. 1998. Handbook of Simulation: Principles, Methodology, Advances, Applications, and Practice, New York, John Wiley and Sons, Inc.

Beuthe, M. and Bouffioux, C. (2008). Analysing Qualitative Attributes of Freight Transport from Stated Orders of Preference Experiment. Journal of Transport Economics and Policy, 42(1), 105-128. http://www.catchword.com/cgi-bin/cgi?ini=bcandbody=l ... 0080101)42:1L.105;1-

Bowersox, D., Closs, D. and Cooper, M. (2007) Supply Chain Logistics Management, Boston, Mcgraw Hill.

Boyson, S., Han, C. and Macdonald, J. (2011). X-Scm Network Design. In: Harrington, L. B., S., and Corsi, T. (Ed.) X-Scm: The New Science of XTreme Supply Chain Management. New York: Routledge.

Brar, G. and Saini, G. (2011). Milk Run Logistics: Literature Review and Directions. Proceedings of the World Congress On Engineering, July 6 - 8 , 2011, London, UK. 
Cachon, G. and Terwiesch, C. (2009) Matching Supply with Demand: an Introduction to Operations Management, Boston, Mcgraw Hill.

Caputo, A. C., Fratocchi, L. and Pelagagge, P. M. (2005) A Framework for Analysing Long-Range Direct Shipping Logistics. Industrial Management and Data Systems, 105(7), 876-899. Doi.org/10.1108/02635570510616094

Caputo, A. C., Fratocchi, L. and Pelagagge, P. M. (2006) A Genetic Approach for Freight Transportation Planning. Industrial Management and Data Systems, 106(5), 719-738. Doi.org/10.1108/02635570610666467

Caputo, M. and Mininno, V. (1996) Internal, Vertical and Horizontal Logistics Integration in Italian Grocery Distribution. International Journal of Physical Distribution and Logistics Management, 26(9), 64-90. Doi.org/10.1108/09600039610149101

Carinic, T. (1999) Long-Haul Freight Transportation. In: Hall, R. W. (Ed.) Handbook of Transportation Science. Dordrecht: Kluwer Academic Publishers.

Cherikh, M.(2000) On The Effect Of Centralization on Expected Profits In A Multi-Location Newsboy Problem. Journal of the Operational Research Society, 51(6), 755. Doi.org/10.1057/palgrave.jors.2600955

Chopra, S. and Meindl, P. (2010) Supply Chain Management: Strategy, Planning, and Operation, New York, Pearson.

Christopher, M. 2005. Logistics And Supply Chain Management: Creating Value-Adding Networks, Harlow, Ft Prentice Hall.

Christopher, M. and Towill, D. (2000) Supply Chain Migration From Lean and Functional to Agile and Customised. Supply Chain Management: an International Journal, 5, 206-213. Doi.org/10.1108/13598540010347334

Cohen, M. and Lee, H. (1989) Resource Deployment Analysis of Global Manufacturing and Distribution Networks. Journal of Manufacturing and Operations Management (2), 81-104.

Cohen, M. and Moon, S. (1990) Impact of Production Scale Economies, Manufacturing Complexity, and Transportation Costs on Supply Chain Facility Networks. Journal of Manufacturing and Operation Management, 6, 269-292.

Coyle, J., Langley, J., Gibson, B., Novack, R. and Bardi, E. (2009) Supply Chain Management: A Logistics Perspective, Mason, South-Western Cengage Learning.

Crandall, R., Crandall, W. and Chen, C. (2010) Principles of Supply Chain Management, London, Crc Press Taylor and Francis Group.

CSCMP(2012, September 20) Milk Run. Council of Supply Chain Management Professional. Available from:

http://cscmp.org/digital/glossary/glossary.asp

Du, T., Wang, F. K. and Lu, P.-Y. (2007) A Real-Time Vehicle-Dispatching System for Consolidating Milk Runs. Transportation Research Part E: Logistics And Transportation Review, 43(5), 565-577. Doi.org/10.1016/j.tre.2006.03.001

Eisenhardt, K. M. and Graebner, M. E. (2007) Theory Building from Cases: Opportunities and Challenges. Academy of Management Journal, 50, 25-32.Doi.org/10.5465/amj.2007.24160888

Eppen, G. D. (1979) Effects of Centralization On Expected Costs In a Multi-Location Newsboy Problem. Management Science, $25(5), 498-501$. www.jstor.org/stable/2630280

Esri (2012, September 20) Top Five Benefits Of Gis. Available from: http://www.gis.com/content/top-five-benefits-gis

Federgruen, A. and Simchi-Levi, D. (1995) Chapter 4 Analysis of Vehicle Routing and Inventory-Routing Problems. In: M.O. Ball, T. L. M. C. L. M. and Nemhauser, G. L. (Eds.) Handbooks In Operations Research And Management Science. Elsevier.

Fritzsche, R. (2012) Cost Adjustment for Single Item Pooling Models Using a Dynamic Failure Rate: A Calculation for the Aircraft Industry. Transportation Research Part E: Logistics And Transportation Review, 48(6), 1065-1079 Doi.org/10.1016/i.tre.2012.04.003

Gerchak, Y. and Gupta, D. (1991) On Apportioning Costs to Customers In Centralized Continuous Review Inventory Systems. Journal of Operations Management, 10(4), 546-551.Doi.org/10.1016/0272-6963(91)90010-U

Gjerdrum, J., Shah, N. and Papageorgious, L. (2001) Transfer Prices for Multienterprise Supply Chain Optimisation. Industrial and Engineering Chemisry Research, 40, 1650-1660.Doi.org/10.1021/ie000668m

Hall, R. W. (2004) Domicile Selection and Risk Pooling For Trucking Networks. lie Transactions, 36(4), 299-305

Doi.org/10.1080/07408170490247421

Heizer, J. and Render, B. (2001) Operation Management, New Jersey, Prentice Hall.

Hoffmann, F. and Kumar, S. (2010) Globalisation-The Maritime Nexus. In: Grammenos, C. (Ed.) The Handbook of Maritime Economics and Business. 2nd Ed. London: Lloyd's List. 
Jung, J. Y., Blau, G., Pekny, J. F., Reklaitis, G. V. and Eversdyk, D. (2004) A Simulation Based Optimization Approach to Supply Chain Management Under Demand Uncertainty. Computers and Chemical Engineering, 28(10), 2087-2106. Doi.org/10.1016/j.compchemeng.2004.06.006

Lee, D.-J. and Jeong, I.-J. (2009) Regression Approximation for a Partially Centralized Inventory System Considering Transportation Costs. Computers and Industrial Engineering, 56(4), 1169-1176.Doi.org/10.1016/j.cie.2008.06.005

Manivannan, M. (1998) Simulation of Logistics and Transportation Systems. In: Banks, J. (Ed.) Handbook Of Simulation: Principles, Methodology, Advances, Applications, and Practice. New York: John Wiley and Sons, Inc.

Matko, D., Zupancic, B. and Karba, R. (1992) Simulation and Modelling of Continuous Systems, New York, Prentice Hall.

Mckinnon, A. C. and Ge, Y. (2006) The Potential for Reducing Empty Running By Trucks: A Retrospective Analysis. International Journal of Physical Distribution and Logistics Management, 36(5), 391-410. Doi.org/10.1108/09600030610676268

Meepetchdee, Y. and Shah, N. (2007) Logistical Network Design with Robustness And Complexity Considerations. International Journal of Physical Distribution and Logistics Management, 37(3), 201-222.Doi.org/10.1108/09600030710742425

Robson, C. (2002) Real World Research, Oxford, Blackwell.

Schonsleben, P. (2004) Integral Logistics Management: Planning and Control of Comprehensive Supply Chains, London, Crc Press.

Shang, J., Yildirim, T. P., Tadikamalla, P., Mittal, V. and Brown, L. H. 2009. Distribution Network Redesign for MarketingCompetitiveness. Journal Of Marketing, 73(2), 146-163. Doi.org/10.1509/jmkg.73.2.146

Silver, E., Pyke, D. and Peterson, R. (1998) Inventory Management and Production Planning and Scheduling, New York, John Wiley and Sons.

Simchi-Levi, D., Kaminsky, P. and Simchi-Levi, E. (2009) Designing and Managing the Supply Chain: Concepts, Strategies and Case Studies, New York, Mcgraw-Hill.

Slack, N., Chambers, S. and Johnston, R. (2010) Operation Management, Harlow, Ft Prentice Hall.

Swink, M., Melnyk, S., Cooper, M. and Hartley, J. (2011) Managing Operations Across the Supply Chain, New York, Mcgraw-Hill.

Thai, V. V. and Grewal, D. (2005) Selecting The Location of Distribution Centre In Logistics Operations: A Conceptual Framework and Case Study. Asia Pacific Journal of Marketing And Logistics, 17(3), 3-24.Doi.org/10.1108/13555850510672359

Tsiakis, P., Shah, N. and Pentelides, C. (2001) Design of Multi-Echelon Supply Chain Networks Under Demand Uncertainty. Industrial and Engineering Chemistry Research, 40(16), 3585-3604.Doi.org/10.1021/ie0100030

Valten, K. (2009) Mathematical Modelling and Simulation: Introduction for Scientists and Engineers, Weinheim, Wiley-Vch Gmbh and Co. Kgaa.

Westminstercollege (2012, September 20) Geographic Information System. Available from http://www.westminster.edu/staff/athrock/GIS/GIS.pdf

Wisner, J., Leong, G. and Tan, K. (2012) Principles of Supply Chain Management: A Balanced Approach, New York, Cengage Learning. 


\section{Appendix A: Development and Analysis of Simulation Scenarios}

\section{Scenario (I) Decentralised Warehouse + Direct Shipment}

\section{(1) Inventory Cost}

Inventory cost is determined by the average level of inventory and multiple by the inventory unit cost. The average level of inventory is founded on safety stock policies. Safety stock relates to the numerical value of the customer service element, lead time and standard deviation of demand (Schonsleben, 2004). Table 3 shows service levels and their corresponding service factor.

Table 3: Service Level (SL) and Service Factor (SF)

\begin{tabular}{llllllllllll}
\hline SL & $90 \%$ & $91 \%$ & $92 \%$ & $93 \%$ & $94 \%$ & $95 \%$ & $96 \%$ & $97 \%$ & $98 \%$ & $99 \%$ & $99.9 \%$ \\
\hline SF (z) & 1.29 & 1.34 & 1.41 & 1.48 & 1.56 & 1.65 & 1.75 & 1.88 & 2.05 & 2.33 & 3.08 \\
\hline
\end{tabular}

Source: (Simchi-Levi et al., 2009)

As inventory level for decentralised warehouse (current warehouse) is supplied by cooperation A, inventory cost equals quantity multiplied by unit costs plus fixed costs.

\section{(2) Inventory Utilisation}

Inventory turnover ratio (ITR) parameter is used in representation of inventory utilisation, thus in this paper, it provides an effective approach to inventory utilisation quantification. The ITR as reviewed by (Schonsleben, 2004) is:

Inventoryory turnover ratio $(I T R)=\frac{\text { annual sales }}{\text { average inventory level }}$

\section{(3) Transportation Cost}

\section{Distance}

Given the operations of 'Corporation A' (the case study), the distances of distribution routes were measured by GIS for scenario (I), representing the current network of the firm. With input data of departure and destination, tools were used for route distance measurement and optimisation-planning to reaching solutions for different customers' requirements.

Table 4: Algorithm for Truckload Analysis for Scenario (I)

\begin{tabular}{ccccccc}
\hline D & Unit & Dis & Drop-in/trip & No. of trips (Round up to) & Distance & Total Distance \\
\hline$x_{i}$ & $m$ & $d_{i}^{M R}$ & $\frac{x_{i}}{J}$ & {$\left[\frac{x_{i}}{J \cdot m}\right\rceil$} & $d_{i}^{M R} \cdot\left\lceil\frac{x_{i}}{J \cdot m}\right\rceil \sum_{i=1}^{I} d_{i}^{M R} \cdot\left\lceil\frac{x_{i}}{J \cdot m}\right\rceil$ \\
\hline
\end{tabular}

Note: Dis $=$ Distance, $\mathrm{D}=$ demand, and $[$.$\rceil takes the ceiling integer.$

To determine the number of trips, drop-in load/trip in CDC was calculated. The number of trips is an integer which takes the ceiling integer. Then, the distance based on the number of total trips can be determined. (Table 4)

\section{Freight}

The freight rates (GBP per tonne-km) (f), were supplied by Corporation A, and constituted integral elements in the calculation of transportation cost (freight). This can be calculated by freight rate $(f) \times$ Distance $\left(d_{i}^{M R} \cdot n\right)$.

\section{(4) Determination of Truck Utilisation}

In this light, table 5 presents algorithms which are developed to support the determination of truck utilisation in scenario (I). 
Table 5: Algorithm for Truckload Utilisation Rate for Scenario (I)

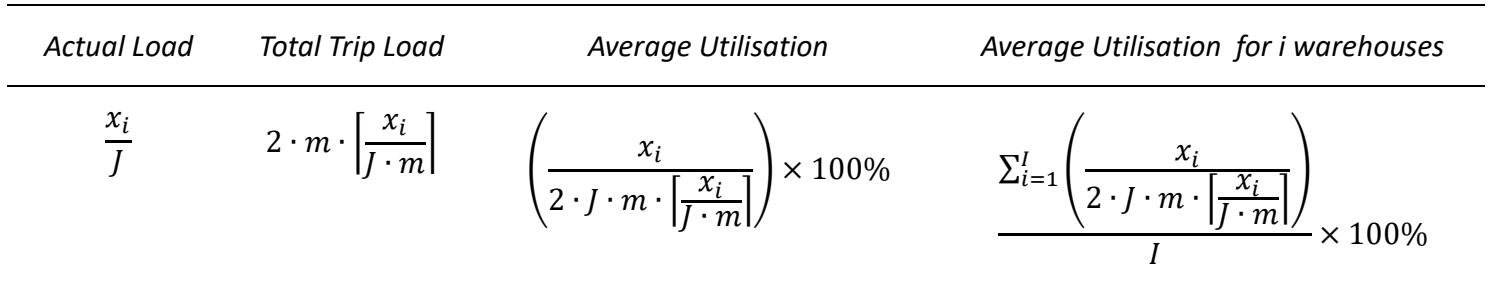

Table 5, vehicle utilisation is the ratio between actual load and truck load-capacity utilisation. Here, the actual load tons to RDCs, equals required tons of goods multiplied by quantity of demand in each warehouse. The total trip load is the return trip ( 2 times) multiplied by unit of truckload, quantity of demand in each warehouse, and number of trips. The average utilisation for $i$ warehouses is the average of all utilisation.

\section{Scenario (II) Decentralised Warehouse + Milk Run Shipment}

\section{(1) Identification of Transportation Cost}

\section{Distance}

The distance measurement hinges on analysing different of truckloads that influence the number of trips a vehicle would make. As shown in table 6, In a trip, the rate of load pick-up (i.e. load/trip) via each warehouse $(i=1,2, \ldots, l)$ is $\frac{x_{i} \cdot m}{\sum_{i=1}^{l} x_{i}}$.

Table 6: Algorithms for the pick-up load per trip at warehouse $i$

\begin{tabular}{lc}
\hline Location (Warehouses) & The pick-up load per trip at warehouse $i$ \\
\hline$i=1,2, \ldots, l$ & $\frac{x_{i} \cdot m}{\sum_{i=1}^{I} x_{i}}$ \\
\hline
\end{tabular}

On the basis of table 6 , the number of trips in terms of rate of truckload per vehicle can be measured. Table 7 shows the relationship between declining rate of truckload and trips, and also the decline of truckload in different trips in per warehouse. The decline amount of goods in each trip is followed by the decreasing rate of truckload.

Table 7: Analysis of the Relationship between Rate of Truckload and Trips in Four Plants in Scenario (II)

\begin{tabular}{|c|c|c|c|c|c|}
\hline Warehouse & Rate & Tons & 1st Trip & 2nd Trip & $n$ trips \\
\hline$i=1,2, \ldots, l$ & $\frac{x_{i} \cdot m}{\sum_{i=1}^{I} x_{i}}$ & $x_{i}$ & $x_{i}-\frac{x_{i} \cdot m}{\sum_{i=1}^{I} x_{i}}$ & $\left(x_{i}-\frac{x_{i} \cdot m}{\sum_{i=1}^{I} x_{i}}\right)-\frac{x_{i} \cdot m}{\sum_{i=1}^{I} x_{i}}$ & $x_{i}-n \cdot\left(\frac{x_{i} \cdot m}{\sum_{i=1}^{I} x_{i}}\right)$ \\
\hline & Total & $\sum_{i=1}^{I} x_{i}$ & $\sum_{i=1}^{I} x_{i}-m$ & $\sum_{i=1}^{I} x_{i}-2 \cdot m$ & $\sum_{i=1}^{I} x_{i}-n \cdot m$ \\
\hline
\end{tabular}

The distance of one trip was measured by GIS, therefore, the total distance was determined multiplying 1 st trip distance $\left(d_{2}\right)$ by the number of trips $(n)$.

\section{Freight}

Given the freight rate (GBP per Ton/Km) (f) supplied by Corporation A, transportation cost can be calculated, using the equation; freight $($ transportation cost $)=$ Freight rate $(f) \times$ Distance $\left(d_{2} \cdot n\right)$. 


\section{(3) Determination of Truck Capacity Utilisation}

The table 8 shows the algorithm for truck capacity utilisation rate for scenario (II).

Table 8: Algorithms for the Truckload Utilisation Rate for Scenario (II)

\begin{tabular}{|c|c|c|c|c|c|}
\hline Pick-up Site & $\begin{array}{c}\text { Depo } \\
t\end{array}$ & $\begin{array}{c}\text { Warehouse } \\
\text { A }(i=1)\end{array}$ & $\begin{array}{c}\text { Warehouse } \\
\text { B (i=2) }\end{array}$ & & Warehouse $i$ \\
\hline Load & 0 & $x_{1}^{L / T}$ & $\begin{array}{l}x_{1}^{L / T} \\
+x_{2}^{L / T}\end{array}$ & & $x_{1}^{L / T}+x_{2}^{L / T}+x_{3}^{L / T}+\cdots+x_{I}^{L / T}$ \\
\hline $\begin{array}{l}\text { Drop-in } \\
\text { Site }\end{array}$ & \multicolumn{3}{|c|}{$R D C J(j=1)$} & \multicolumn{2}{|r|}{$R D C A-D e p o t(j=10)$} \\
\hline Load & & $\sum_{i=1}^{I} x_{i}^{L / T}-\sum_{j=}^{J}$ & $\frac{\cdot m}{J}$ & \multicolumn{2}{|r|}{0} \\
\hline \multicolumn{4}{|c|}{ Actual Load } & Full Load & Utilisation rate \\
\hline \multicolumn{4}{|c|}{$\begin{array}{l}{\left[i x_{1}^{L / T}+(i-1) x_{2}^{L / T}+\cdots+x_{i}^{L /}\right.} \\
\left.\sum_{i=1}^{I} x_{i}^{L / T}-\sum_{j=1}^{J} \frac{j \cdot m}{J}\right)\end{array}$} & $\begin{array}{l}m \cdot(I+J \\
+1)\end{array}$ & $\frac{\left[i x_{1}^{L / T}+(i-1) x_{2}^{L / T}+\cdots+x_{I}^{L / T}\right]+\left(J \cdot \sum_{i=1}^{I} x_{i}^{L / T}-\sum_{j=1}^{J} \frac{j \cdot m}{J}\right)}{m \cdot(I+J+1)}$ \\
\hline
\end{tabular}

Load in a truck is in a constant growth trend in the order of A-B-C-D with pick-up rate (e.g. $\left.\frac{x_{i} \cdot m}{\sum_{i=1}^{l} x_{i}}\right)$. The tons of loads peak at final warehouse D, and afterwards, the truck drops specific rate of goods (i.e. $\frac{m}{J}$ ) in each RDC, and then returns to transportation depot with ETL.

\section{Scenario (III) Centralised Warehouse + All shipments via Distribution Centre}

\section{(1) Identification of CDC/Warehouse Location}

Scenario (III) and the following scenarios (IV) and (V) are based on the centralised distribution network, thus there is the need to identify $\mathrm{CDC}$ /warehouse locations. For this location determination, weighted average method was used, and is discussed as follows:

The coordinate of centre of gravity of CDC can be found by (Thai and Grewal, 2005), On the basis of the equation, the coordinate of CDC $\overline{C_{C D C}}$ is determined by weight $x_{i}$ (demand volume in manufactures and RDCs) and coordinate of manufactures and RDCs, with the notation of $C_{i}$ and $C_{j}$, respectively.

$\overline{C_{C D C}}=\frac{\sum_{i=1}^{I} x_{i} \cdot C_{i}+\frac{\sum_{i=1}^{I} x_{i}}{J} \cdot J \cdot C_{j}}{\sum_{i=1}^{I} x_{i}+\frac{\sum_{i=1}^{I} x_{i}}{J} \cdot J}$

Where: the total volumes in all warehouses are equally distributed to $J$ RDCs, hence the volumes for each $\operatorname{RDC}$ are $\frac{\sum_{i=1}^{I} x_{i}}{J}$. 


\section{(2) Inventory Cost}

Assuming inventory aggregation takes place in the $C D C$, there is a need to assess the distribution of aggregated demand. The aggregated demand is normally distributed, with an average of $D^{C}$ standard deviation of $\sigma_{D}^{C}$, a variance of var (DC) and an assumption of lead-time ( $L$ ) (Chopra and Meindl, 2010). Therefore, average inventory in centralised CDC/warehouse is:

Average inventory level $=z \cdot \sqrt{L} \cdot \sigma_{D}^{C}+\frac{Q}{2}$

[Note: The quantity $(Q)$ in equation below represents Economic Order Quantity (EOQ) model; the data $k$ and $h$ are supplied by "Cooperation A"]

$\left[\mathrm{Q}=\sqrt{\frac{2 \mathrm{~K} \times \mathrm{AVG}}{\mathrm{h}}}\right]$

Additionally, it is important to note that the CoV is a ratio used in evaluating the impacts of uncertainty by initiating risk-pooling strategy, i.e. with demand mean $(\mu)$ and demand of $\sigma$, results in:

$\operatorname{CoV}=\frac{\sigma}{\mu}$

The CoV measures the size of the uncertainty relative to the demand (Chopra and Meindl, 2010 ; Simchi-Levi et al., 2009).

\section{(3) Transportation Cost}

Remembering that for inventory utilisation, the algorithms for all 5 scenarios are the same, attention is hereby given to developing equations for the determination of transportation cost in centralised scenario (III).

\section{Distance}

Table 9: Algorithms for Truckload and Distance in Scenario (III)

\begin{tabular}{|c|c|c|c|c|c|c|c|c|c|}
\hline \multicolumn{5}{|c|}{$\begin{array}{l}\text { From Factory to CDC (1st transportation } \\
\text { segment ) }\end{array}$} & \multicolumn{5}{|c|}{ From CDC to RDCs (2nd transportation segment) } \\
\hline \multirow{2}{*}{ D } & \multicolumn{2}{|c|}{ Truckload Analysis } & \multicolumn{2}{|c|}{ Distance } & \multicolumn{3}{|c|}{ Truckload Analysis } & \multicolumn{2}{|c|}{ Distance } \\
\hline & Unit & $\begin{array}{l}\text { Drop-in/trip } \\
\text { Round up to }\end{array}$ & RW & Distance & \multicolumn{5}{|c|}{ Round up to } \\
\hline$x_{i}$ & $m$ & $\left\lceil\frac{x_{i}}{m}\right\rceil$ & $d_{i}^{3 M C}$ & $\left\lceil\frac{x_{i}}{m}\right\rceil \cdot d_{i}^{3 M C}$ & $\sum_{i=1}^{I} x_{i}$ & $\frac{\sum_{i=1}^{I} x_{i}}{J}$ & $\left\lceil\frac{\sum_{i=1}^{I} x_{i}}{J \cdot m}\right\rceil$ & $d_{j}^{3 C R}$ & $\begin{array}{l}\left\lceil\frac{\sum_{i=1}^{I} x_{i}}{J \cdot m}\right\rceil \\
\cdot d_{J}^{3 C R}\end{array} \mid$ \\
\hline & ance & & \multicolumn{7}{|c|}{$\sum_{i=1}^{I}\left\lceil\frac{x_{i}}{m}\right\rceil \cdot d_{i}^{3 M C}+\left\lceil\frac{\sum_{i=1}^{I} x_{i}}{J \cdot m}\right\rceil \cdot \sum_{j=1}^{J} d_{j}^{3 C R}$} \\
\hline
\end{tabular}

Key: RW Round Way; D Demand and [.] takes the ceiling integer

Table 9 demonstrates the algorithm for analysing truckload and distance. The total distance is the sum of the two transportation segments.

\section{Freight}

As the freight rate (GBP per Ton/Km) $(f)$ is produced, freight can be counted, using freight=Freight rate $(f) \times$ Total Distance. 


\section{(5) Determination of Truck Capacity Utilisation}

Table 10: Algorithms for truck utilisation in Scenario (III)

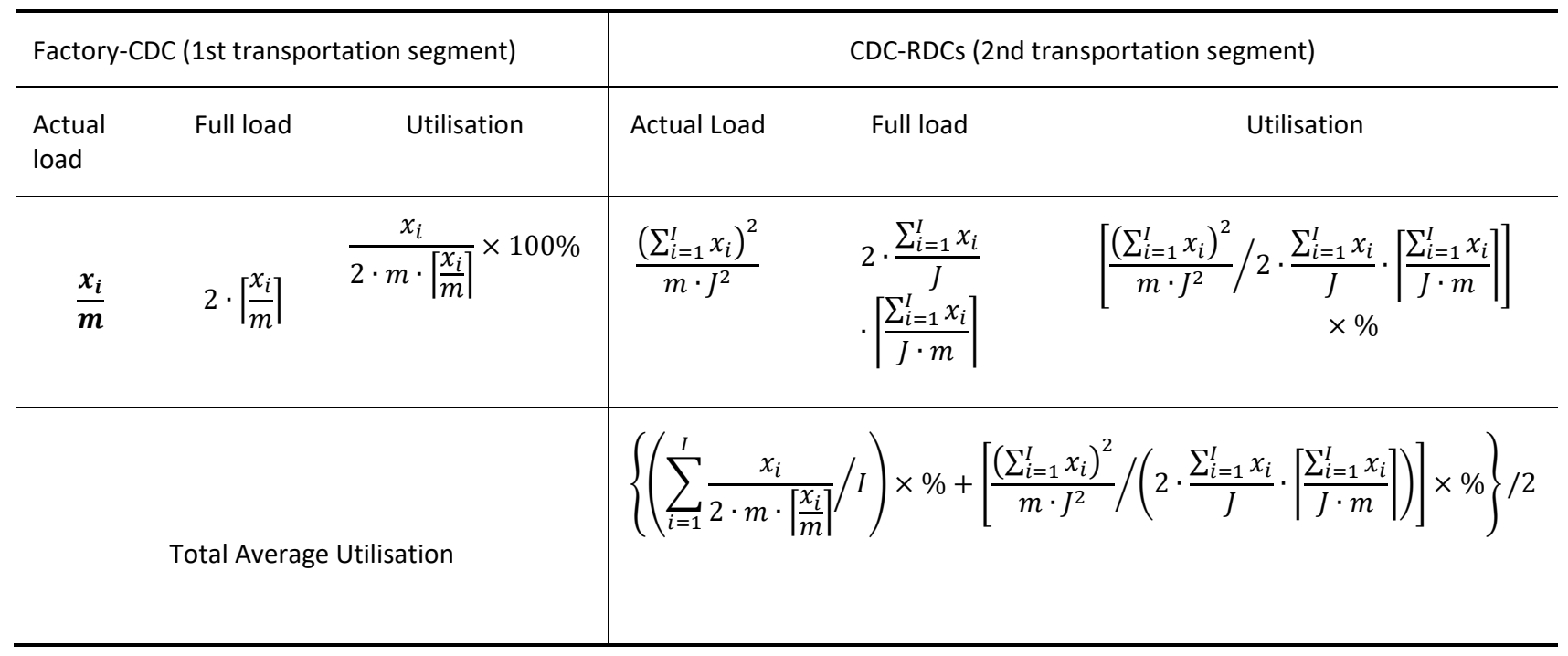

In table 10, equations to enable the determination of truck capacity utilisation is presented, as calculated based on the two transport segments of scenario (III). The total truck capacity utilisation is calculated by obtaining the average utilisation rate of the two transportation segments.

\section{Scenario (IV) Centralised Warehouse + Shipping via DC Using Multi-Route Milk Run}

\section{(1) Transportation Cost}

\section{Distance}

Distance attributes are integral influence-factors on transportation cost. Table 11 demonstrates the algorithms of truckload and distance in scenario (IV). In this case, truckload analysis also consists of two transportation segments. In the 1st transport segment is similar to scenario (III)

Table 11: Algorithm for the Assessment of Truckload and Distance in Scenario (IV)

\begin{tabular}{|c|c|c|c|c|c|c|c|c|c|c|c|}
\hline \multicolumn{5}{|c|}{ Factory - CDC (1st transportation segment) } & \multicolumn{7}{|c|}{ From CDC to RDCs (2nd transportation segment) } \\
\hline \multirow[b]{2}{*}{$D$} & \multicolumn{2}{|c|}{ Truckload Analysis } & \multicolumn{2}{|c|}{ Distance Analysis } & \multicolumn{4}{|c|}{ Truckload Analysis } & \multicolumn{3}{|c|}{ Distance Analysis } \\
\hline & $\begin{array}{c}\text { Uni } \\
t\end{array}$ & $\begin{array}{l}\text { Drop- } \\
\text { in/Round }\end{array}$ & RW & Distance & Load & $\begin{array}{l}\text { Drop- } \\
\text { in/Trip }\end{array}$ & Site & $\begin{array}{l}\text { Each } \\
\text { needs }\end{array}$ & $\begin{array}{c}\text { Trip } \\
\text { Round up to }\end{array}$ & $\begin{array}{l}\text { Dis/ } \\
\text { Trip }\end{array}$ & Distance \\
\hline$x_{i}$ & M & $\left\lceil\frac{x_{i}}{m}\right\rceil$ & $d_{i}^{4 M C}$ & $\left\lceil\frac{x_{i}}{m}\right\rceil \cdot d_{i}^{4 M C}$ & $\sum_{i=1}^{I} x_{i}$ & $\frac{\sum_{i=1}^{I} x_{i}}{J}$ & $o$ & $o \cdot \frac{\sum_{i=1}^{I} x_{i}}{J}$ & $\left\lceil\frac{o \cdot \sum_{i=1}^{I} x_{i}}{J \cdot m}\right\rceil$ & $d_{1}^{4 C R}$ & $\left\lceil\frac{o \cdot \sum_{i=1}^{I} x_{i}}{J \cdot m}\right\rceil \cdot d_{1}^{4 C R}$ \\
\hline & & & & & & & $P$ & $p \cdot \frac{\sum_{i=1}^{I} x_{i}}{j}$ & $\left\lceil\frac{p \cdot \sum_{i=1}^{I} x_{i}}{J \cdot m}\right\rceil$ & $d_{2}^{4 C R}$ & $\left\lceil\frac{p \cdot \sum_{i=1}^{I} x_{i}}{J \cdot m}\right\rceil \cdot d_{2}^{4 C R}$ \\
\hline & & & & & & & $Q$ & $q \cdot \frac{\sum_{i=1}^{I} x_{i}}{j}$ & $\left\lceil\frac{q \cdot \sum_{i=1}^{I} x_{i}}{J \cdot m}\right\rceil$ & $d_{3}^{4 C R}$ & $\left\lceil\frac{q \cdot \sum_{i=1}^{I} x_{i}}{J \cdot m}\right\rceil \cdot d_{3}^{4 C R}$ \\
\hline
\end{tabular}




\begin{tabular}{|l|c|c|c|c|c|}
\hline \multicolumn{1}{|c|}{} & $r$ & $r \cdot \frac{\sum_{i=1}^{I} x_{i}}{j}\left\lceil\left\lceil\frac{r \cdot \sum_{i=1}^{I} x_{i}}{J \cdot m}\right\rceil \frac{d_{4}^{4 C R}\left\lceil\cdot \sum_{i=1}^{I} x_{i}\right.}{J \cdot m}\right\rceil \cdot d_{4}^{4 C R} \mid$ \\
\hline Total Distance $=$ & $\sum_{i=1}^{I}\left\lceil\frac{x_{i}}{m}\right\rceil \cdot d_{i}^{4 M C}+\left\lceil\frac{o \cdot \sum_{i=1}^{I} x_{i}}{J \cdot m}\right\rceil \cdot d_{1}^{4 C R}+\left\lceil\frac{p \cdot \sum_{i=1}^{I} x_{i}}{J \cdot m}\right\rceil \cdot d_{2}^{4 C R}+\left\lceil\frac{q \cdot \sum_{i=1}^{I} x_{i}}{J \cdot m}\right\rceil \cdot d_{3}^{4 C R}+\left\lceil\frac{r \cdot \sum_{i=1}^{I} x_{i}}{J \cdot m}\right\rceil \cdot d_{4}^{4 C R}$ \\
\hline
\end{tabular}

With special change in the 2 nd transportation segment, goods are delivered to different RDCs $(J=10)$ via $4(0, p, q, r)$ different routes. Each route is distributed to designed close-by locations. The numbers of round-trips for each of the routes are respectively represented in table 11 . Afterwards the distances of CDC-RDCs are obtained according to the number of round trips. Finally, the total distances are the sum of distances of the two transportation segments.

Freight

Freight can be obtained, based on: freight=Freight rate $(f) *$ Total Distance.

\section{(4) Truck Capacity Utilisation}

Table 12: Algorithm for Truck Utilisation in Scenario (IV)

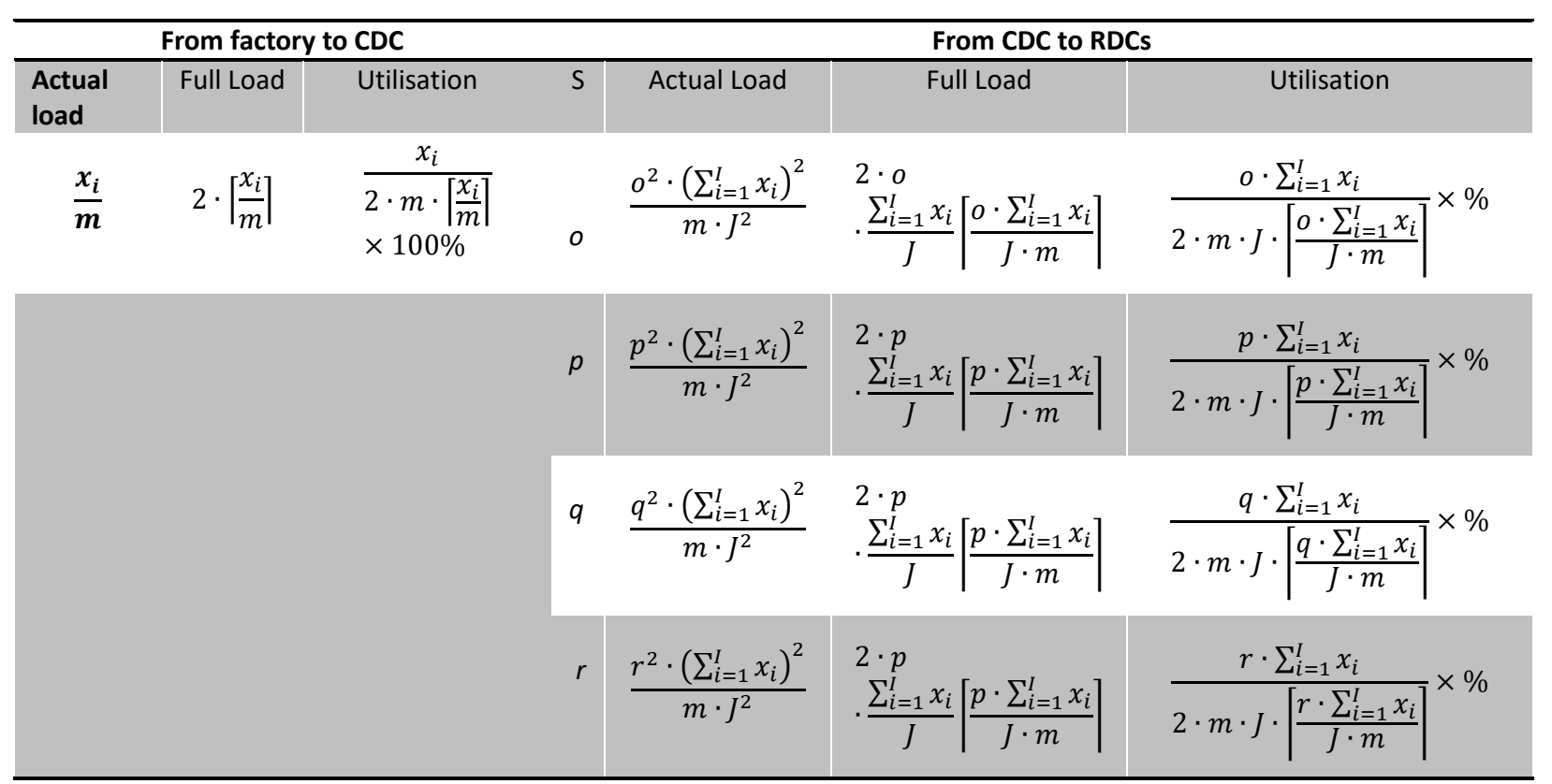

Key: S means Site (number of the sites called to by truck)

Because the scenario (IV) is integrated with scenario (II) and (III), calculation of total truckload rate is the combination of two procedures. The table 12 shows the specific truckload analysis in scenario (IV). Finally, determination of the total truck capacity utilisation is the average of the two transportation segments is calculated. 


\section{Scenario (V) Centralised Warehouse + Shipping via DC with single-route Milk Run}

(1) Determination of truckload, distance, and freight

Distance

Table 13: Algorithm of Truckload and Distance in Scenario (V)

\begin{tabular}{|c|c|c|c|c|c|c|c|c|}
\hline \multirow{3}{*}{ Demand } & \multicolumn{4}{|c|}{ From factory to CDC (1st transportation segment) } & \multicolumn{4}{|c|}{ From CDC to RDCs (2nd transportation segment) } \\
\hline & \multicolumn{2}{|c|}{ Truckload analysis } & \multicolumn{2}{|c|}{ Distance } & \multicolumn{2}{|c|}{ Truckload Analysis } & \multicolumn{2}{|c|}{ Distance } \\
\hline & Unit & Drop-in/Round up to & RW & Distance & Load & $n$ Trip/load & RW & Distance \\
\hline$x_{i}$ & $m$ & $\left\lceil\frac{x_{i}}{m}\right\rceil$ & $d_{i}^{5 M C}$ & $\left\lceil\left\lceil\frac{x_{i}}{m}\right\rceil \cdot d_{i}^{5 M C}\right.$ & $\sum_{i=1} x_{i}$ & $\sum_{i=1} x_{i}-n \cdot m$ & $d^{5 C R}$ & $d^{5 C R} \cdot n$ \\
\hline $\begin{array}{r}\text { Total } \\
\text { Distance }\end{array}$ & & & & $\sum_{i=1}^{I}\left\lceil\frac{x_{i}}{m}\right\rceil$. & $d^{5 c}$ & & & \\
\hline
\end{tabular}

Total distances are the sum of two transportation segments (table 13). In the 1st transportation segment, distance $\left[\left\lceil\frac{x_{i}}{m}\right] \cdot d_{i}^{5 M C}\right]$, can be calculated by multiplying the number of trips and distance covered per trip. For the 2 nd transportation segment, the truckload analysis influences the number of trips needed and is similar to the milk run scenario (II), as shown in Figure 3 . The numbers of trips are computed based on the truckload parameters, namely $\sum_{i=1}^{I} x_{i}-n \cdot m$. Finally, the distance for the 2 nd transportation segment, $\left(d^{5 C R}\right)$, can be obtained by the multiplication of the number of trips and the distance covered per milkrun trip. Consequently, the total distances are the sum of the 2 transportation segments, as shown.

Freight: As in previous cases, freight $=$ Freight rate $(f) \times$ Total Distance [note: Freight rate $($ GBP per Ton/Km) $(f)$ is supplied.

\section{(2) Determination of Truck Capacity Utilisation}

At this point, the algorithm for determination of truck capacity utilisation in scenario (V) is presented in table 14 and consequently explained.

Table 14: Algorithm for Truck Utilisation in Scenario (V)

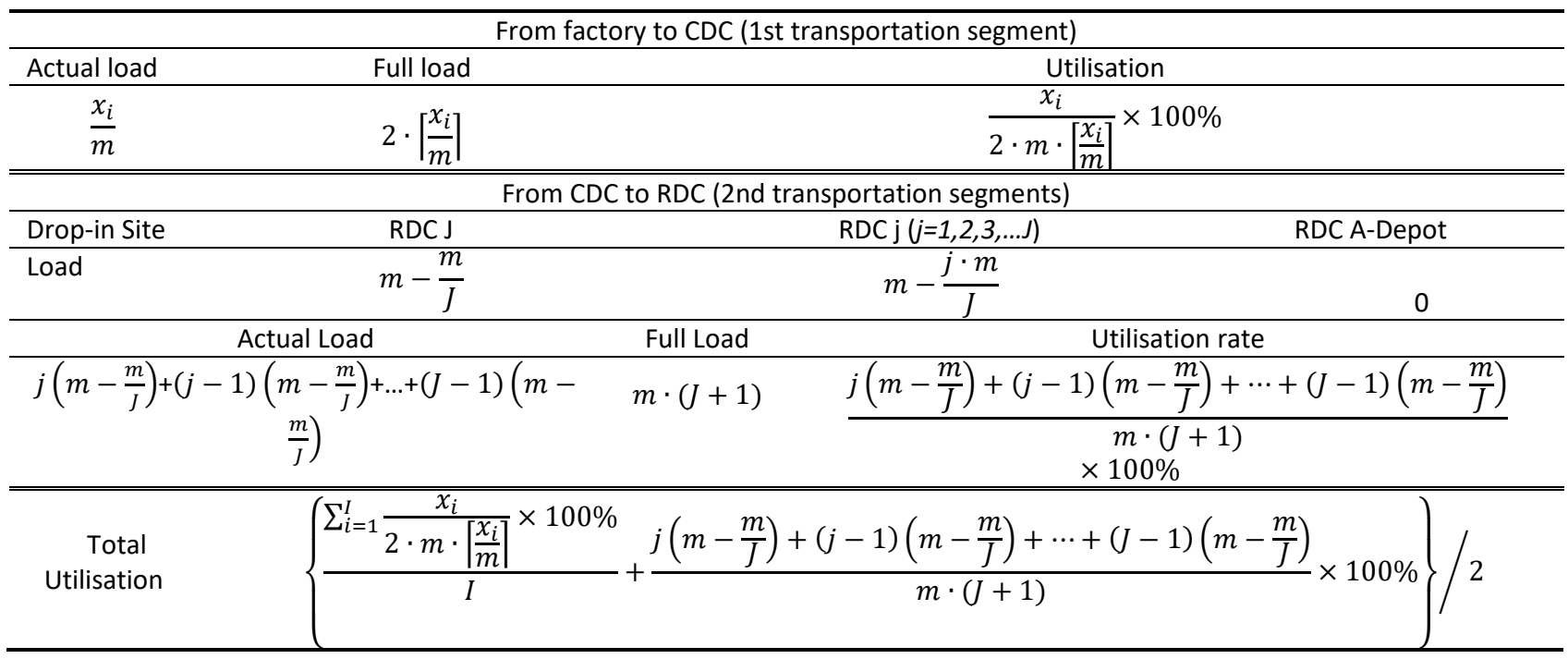

Initially, for the 1st transportation segment, truck capacity utilisation ratio is obtained in the same manner of scenario (III). In the 2nd transportation segment, the ratio is in a constant decline from the CDC back to the same CDC via the designated RDCs. Thus, the truck capacity utilisation is the ratio between the actual truck capacity utilisation and assumed truck capacity utilisation. In this light, the total truck capacity utilisation for the scenario $(\mathrm{V})$ is the average of the two transportation segments, as finally shown in table 13. 


\section{Appendix B: Annual Demands of 4 Types of Goods in 4 Manufactories}

\begin{tabular}{|c|c|c|c|c|c|c|c|c|c|c|c|c|c|c|}
\hline \multicolumn{14}{|c|}{ Type A(White Board) } & \multirow{2}{*}{$\begin{array}{l}\text { Average } \\
\text { Demand }\end{array}$} \\
\hline Month & 1 & 2 & 3 & 4 & 5 & 6 & 7 & 8 & 9 & 10 & 11 & 12 & Total & \\
\hline Mill A & 176 & 153 & 182 & 180 & 175 & 166 & 167 & 213 & 234 & 244 & 285 & 236 & 2411 & 200.92 \\
\hline Mill B & 142 & 98 & 89 & 120 & 105 & 104 & 103 & 205 & 271 & 350 & 360 & 370 & 2317 & 193.08 \\
\hline Mill C & 140 & 134 & 140 & 123 & 133 & 137 & 151 & 125 & 156 & 137 & 144 & 135 & 1655 & 137.92 \\
\hline Mill D & 160 & 134 & 142 & 148 & 139 & 128 & 135 & 140 & 136 & 152 & 164 & 174 & 1752 & 146.00 \\
\hline Total & 618 & 519 & 553 & 571 & 552 & 535 & 556 & 683 & 797 & 883 & 953 & 915 & 8135 & 677.92 \\
\hline \multicolumn{14}{|c|}{ Type B (Ivory Board) } & Average \\
\hline Month & 1 & 2 & 3 & 4 & 5 & 6 & 7 & 8 & 9 & 10 & 11 & 12 & Total & Demand \\
\hline Mill A & 132 & 143 & 122 & 130 & 125 & 176 & 207 & 233 & 254 & 264 & 275 & 286 & 2347 & 195.58 \\
\hline Mill B & 102 & 198 & 189 & 120 & 105 & 104 & 103 & 235 & 151 & 230 & 220 & 240 & 1997 & 166.42 \\
\hline Mill C & 130 & 134 & 140 & 123 & 133 & 137 & 151 & 125 & 156 & 177 & 174 & 185 & 1765 & 147.08 \\
\hline Mill D & 140 & 134 & 142 & 148 & 139 & 128 & 135 & 140 & 136 & 132 & 134 & 134 & 1642 & 136.83 \\
\hline Total & 504 & 609 & 593 & 521 & 502 & 545 & 596 & 733 & 697 & 803 & 803 & 845 & 7751 & 645.92 \\
\hline
\end{tabular}

\begin{tabular}{|c|c|c|c|c|c|c|c|c|c|c|c|c|c|c|}
\hline \multicolumn{14}{|c|}{ Type C (carbon free paper) } & \multirow{2}{*}{$\begin{array}{l}\text { Average } \\
\text { Demand }\end{array}$} \\
\hline Month & 1 & 2 & 3 & 4 & 5 & 6 & 7 & 8 & 9 & 10 & 11 & 12 & Total & \\
\hline Mill A & 122 & 127 & 122 & 130 & 125 & 136 & 127 & 133 & 144 & 154 & 155 & 156 & 1631 & 135.92 \\
\hline Mill B & 162 & 158 & 179 & 145 & 155 & 144 & 153 & 165 & 151 & 143 & 165 & 160 & 1880 & 156.67 \\
\hline Mill C & 116 & 123 & 130 & 132 & 125 & 134 & 118 & 132 & 121 & 130 & 169 & 175 & 1605 & 133.75 \\
\hline Mill D & 134 & 123 & 134 & 127 & 132 & 145 & 137 & 144 & 126 & 140 & 160 & 172 & 1674 & 139.50 \\
\hline Total & 534 & 531 & 565 & 534 & 537 & 559 & 535 & 574 & 542 & 567 & 649 & 663 & 6790 & 565.83 \\
\hline \multicolumn{14}{|c|}{ Type D (Thermal Paper) } & Average \\
\hline Month & 1 & 2 & 3 & 4 & 5 & 6 & 7 & 8 & 9 & 10 & 11 & 12 & Total & Demand \\
\hline Mill A & 134 & 122 & 121 & 121 & 131 & 145 & 121 & 134 & 135 & 125 & 126 & 126 & 1541 & 128.42 \\
\hline Mill B & 121 & 115 & 125 & 131 & 112 & 114 & 115 & 111 & 119 & 118 & 120 & 187 & 1488 & 124.00 \\
\hline Mill C & 38 & 34 & 22 & 0 & 0 & 0 & 26 & 23 & 25 & 35 & 46 & 47 & 296 & 24.67 \\
\hline Mill D & 7 & 0 & 0 & 0 & 23 & 22 & 15 & 16 & 18 & 20 & 22 & 34 & 177 & 14.75 \\
\hline Total & 300 & 271 & 268 & 252 & 266 & 281 & 277 & 284 & 297 & 298 & 314 & 394 & 3502 & 291.83 \\
\hline
\end{tabular}

\begin{tabular}{lr}
\hline \multicolumn{2}{c}{ Total Demand } \\
\hline Mill A & 7930 \\
Mill B & 7682 \\
Mill C & 5321 \\
Mill D & 5245 \\
Total & 26178 \\
\hline
\end{tabular}

Unit: Tonnage 